IVAN MUNHOZ PASIN

\title{
ANÁLISE POR SUBTRAÇÃO RADIOGRÁFICA DIGITAL LINEAR DO TRATAMENTO DE DEFEITOS INFRA-ÓSSEOS HUMANOS DE 2 OU 3 PAREDES POR MEIO DE RETALHO DE ESPESSURA TOTAL REPOSTO ASSOCIADO OU NÃO À PROTEÍNA DERIVADA DA MATRIZ DO ESMALTE
}




\section{Ivan Munhoz Pasin}

Análise por subtração radiográfica digital linear do tratamento de defeitos infra-ósseos humanos de 2 ou 3 paredes por meio de retalho de espessura total reposto associado ou não à proteína derivada da matriz do esmalte

Dissertação apresentada à Faculdade de Odontologia da Universidade de São Paulo para obter o título de Mestre, pelo Programa de Pós-graduação em Odontologia.

Área de Concentração: Periodontia

Orientador: Prof. Dr. Luiz A. P. A. de Lima 


\section{FOLHA DE APROVAÇÃO}

Pasin IM. Análise por subtração radiográfica digital linear do tratamento de defeitos infra-ósseos humanos de 2 ou 3 paredes por meio de retalho de espessura total reposto associado ou não à proteína derivada da matriz do esmalte [Dissertação de Mestrado]. São Paulo: Faculdade de Odontologia da USP; 2006.

São Paulo, /2006

\section{Banca Examinadora}

1) Prof. Dr.

Titulação:

Julgamento:

Assinatura:

2) Prof. Dr

Titulação:

Julgamento:

Assinatura:

3) Prof. Dr

Titulação:

Julgamento:

Assinatura: 


\section{DEDICATÓRIA}

Dedico este trabalho à minha esposa, Camila Torriani Pasin, pessoa por quem tenho infinito amor, respeito e devoção, e que vem ao longo de 8 anos revelando-me com sua inata simplicidade, a importância do companheirismo, da compreensão mútua e da inspiração divina.

Dedico este trabalho aos meus avós, Atilio Pasini, Helena Carneiro Pasini e Francisco Munhoz que sem dúvida orgulhar-se-iam dele pelo simples fato de eu tê-lo escrito. À Maria Delma Munhoz que transmite seu imenso amor à minha pessoa.

Dedico este trabalho aos meus amados pais, Atilio Pasin Filho e Sônia Maria Munhoz Pasin, que representam a mais pura fidelidade e compaixão por perdoar-me pelas decisões erradas e ensinar-me que o amor familiar é um dos segredos de viver em paz. Vocês jamais cessarão o processo de me ensinar.

Dedico este trabalho às minhas amadas irmãs, Luciana Munhoz Pasin e Andréa Munhoz Pasin, pois sem vocês eu não teria me tornado a pessoa que sou hoje. Dedico também este trabalho à Cecília Torriani, minha cunhada, mas que se mostra com amor de irmã.

Dedico este trabalho aos meus "outros pais", Vicente Torriani Neto e Cleide Baganha Torriani, que souberam acolher-me como vosso filho demonstrando o valor da família, da sinceridade e da alegria de compartilhar e dividir a felicidade com 0 próximo. Orgulho-me de tê-los conhecido.

Dedico este trabalho ao meu orientador, Luis Antonio Pugliesi Alves de Lima, exemplo de integridade e coerência, que ao meio de seu vasto saber conseguiu 
plantar em mim a avidez pelo conhecimento e a vontade de seguir adiante. Considero a forma de trabalharmos muito prazerosa.

Por fim, dedico este trabalho ao Prof. Titular Francisco Emílio Pustiglioni, pessoa da qual tive ótimas impressões logo em nosso primeiro encontro. Não tenho dúvidas de que seu coração, bondade, postura paternalista e valorização familiar engrandecem seus ensinamentos. 


\section{AGRADECIMENTOS}

À grande amiga, Daniela Chambrone, pelo companheirismo, pelos ensinamentos e pela oportunidade de aceitar-me como seu parceiro de trabalho. Sua disposição e dedicação são frutos de minha inspiração.

À Débora Tokarewicz, pela ajuda e interesse, pelo companheirismo e aplicação aos estudos.

Aos professores e colegas de trabalho, Cláudio Mendes Panutti e Marina Clemente Conde, pelas inúmeras contribuições e trabalho em conjunto.

À minha turma, Cássia Tieme Fukuda, Hsu Shao Feng, Priscila Corraini, Fábio Moura Lima, Ricardo Taky, Giovane Gomes, Valéria Gondin, Carla Damante, Adriane Yaeko Togashi, Verônica Carvalho, por todos os momentos de companheirismo, alegria, diversão, respeito mútuo e trabalho....muito trabalho. Considero vocês "A TURMA" especial.

Aos professores da disciplina, Girogio de Micheli e Roberto Fraga Lotufo, pelos ensinamentos, pelas oportunidades e pelo exemplo de dedicação ao ensino e à pesquisa.

Aos professores da disciplina, Giuseppe Alexandre Romito, Silvia Rosana Soares Carneiro e Marco Antônio Paupério Georgetti, pelas contribuições nos seminários, considerações e transmissão de conhecimentos.

Ao professor da disciplina de Radiologia, Marcelo Cavalcanti, pelas orientações, considerações e participação nas discussões que surgiram ao longo deste trabalho. Fico grato por sua participação na minha formação como mestre.

À Prof ${ }^{a}$.Dra. llíria Feist, pelas contribuições, sugestões e companheirismo. 
Ao Prof. Titular José Hildebrando Todescan pelas contribuições nos seminários e pelo exemplo de experiência e dedicação à vida acadêmica.

Às funcionárias da disciplina, Márcia Maria dos Santos e Mara Luisa Hortêncio, por estarem sempre presentes, pela paciência e pela amizade.

À funcionária do setor de pós-graduação, Kátia, pelas inúmeras colaborações em todos os momentos necessários.

Aos pacientes desta pesquisa que confiaram em nosso trabalho e participaram sem medir esforços, tornando possível a concretização de mais uma etapa na minha carreira.

À Fundação de Amparo à Pesquisa do Estado de São Paulo (FAPESP) que viabilizou a realização deste trabalho.

Às bibliotecárias da FOUSP pela ajuda e auxílio na confecção deste trabalho. 
Pasin IM. Análise por subtração radiográfica digital linear do tratamento de defeitos infra-ósseos humanos de 2 ou 3 paredes por meio de retalho de espessura total reposto associado ou não à proteína derivada da matriz do esmalte [Dissertação de Mestrado]. São Paulo: Faculdade de Odontologia da USP; 2006.

\section{RESUMO}

A Subtração Radiográfica Digital (SRD) vem sendo vastamente utilizada para inúmeros fins em Odontologia. Uma de suas aplicações é a avaliação do resultado radiográfico de procedimentos regenerativos. Este estudo avaliou radiograficamente defeitos infra-ósseos de 2 ou 3 paredes tratados com a proteína derivada da matriz do esmalte (PME) e/ou o retalho de espessura total reposto (RET). Foram selecionados 11 pacientes ( 3 ? / 8 ?) com periodontite crônica apresentando 2 ou mais defeitos. Antes da cirurgia e após 1 ano foram coletados os dados clínicos e radiográficos. Para a padronização radiográfica foi utilizado um posicionador modificado. Reveloutse os filmes numa processadora automática. As películas foram digitalizadas (500dpi/8bits) em um escaner (SprintScan 35 Plus - Polaroid). Através do programa AxioVision v 3.0 (Carl Zeiss) mediu-se as distâncias da JEC à crista óssea (CO), ao fundo do defeito (FD). Para criar uma escala milimétrica e calibrar a mensuração foi utilizada uma tela quadriculada $(2 \times 2 \mathrm{~mm})$. As porcentagens de mudança óssea (MO) também foram calculadas. Os resultados mostraram perda da CO de 1,8 mm para PME $(\mathrm{MO}=-20,93 \%)$, revelando diferença estatística neste grupo ( $p<0,02$ ), e de $0,9 \mathrm{~mm}$ para RET ( $M O=-10,71 \%$ ), sem diferença entre os grupos. Observou-se maior preenchimento do FD em RET (1,1 mm; MO = 8,14\%) do que em PME $(-0,6 \mathrm{~mm} ; \mathrm{MO}=-3,92 \%)$, com diferença entre os grupos $(\mathrm{p}<0,01)$. Dentro das limitações deste estudo, conclui-se que através da análise por SRD 
linear o tratamento convencional de defeitos infra-ósseos humanos promoveu melhores resultados quando comparado à aplicação da PME.

Palavras-Chave: Técnica de subtração - Radiografia dentária - Técnicas de diagnóstico e procedimentos - Regeneração periodontal - Periodontia 
Pasin IM. Linear radiographic digital subtraction analysis of treatment of human 2 or 3-wall intrabony defects by repositioned flap associated or not with enamel derivative matrix protein [Dissertação de Mestrado]. São Paulo: Faculdade de Odontologia da USP; 2006.

\section{ABSTRACT}

Digital Subtraction Radiographic (DSR) has been widely used for several purposes in Dentistry. Among them is the radiographic evaluation of the results of regenerative procedures. This study evaluated radiographically 2 and 3 wall infra-bony defects which were treated with matrix derivative enamel protein (PME) and/or repositioned flap (RET). Eleven patients (3 ? / 8 ?) with chronic periodontitis were selected, presenting 2 or more defects. Clinical and radiographic data were collected before surgery. A modified filmholder was used to take standardized radiographs. X-ray were developed using an automatic machine. The films were digitized (500dpi/8bits) with the scanner SprintScan 35 Plus (Polaroid). The software AxioVision v 3.0 (Carl Zeiss) was used to measure the distances from the JEC to the alveolar crest (CO), to the bottom of the defect (FD). A grid $(2 \times 2 \mathrm{~mm})$ was used to establish a milimetric scale after calibration. The amount of bone changes (MO) was also calculated. Results have shown loss of bone at the $\mathrm{CO}$ of $1,8 \mathrm{~mm}$ (PME) (MO = -20,93\%), showing statistic significance $(p<0,02)$, and of $0,9 \mathrm{~mm}$ to RET group (MO $=-10,71 \%$ ). No significant differences could be observed when groups were compared. A better fill was observed in the RET group $(1,1 \mathrm{~mm}$; MO = 8,14\%) than in the PME group ($0,6 \mathrm{~mm} ; \mathrm{MO}=-3,92 \%)$, showing statistical significance between groups $(\mathrm{p}<0,01)$. In conclusion, radiographic analysis has shown that conventional treatment of human intra-bony defects promotes better results when compared to the application of PME. 
Keywords: Subtraction technique - Dental radiography - Procedures and diagnostic techniques - Periodontal regeneration - Periodontics 


\section{LISTA DE ILUSTRAÇÕES}

Figura 4.1 - Posicionador radiográfico modificado...........................................36

Figura 4.2- Pinos de troquel paralelos entre si..........................................37

Figura 4.3- Registro oclusal de resina acrílica de uma das regiões a serem operadas

Figura 4.4- Conjunto posicionador - registro oclusal para a padronização das tomadas radiográficas.

Figura 4.5- Anel de resina acrílica.

Figura 4.6- Anel de resina acrílica colocado em posição no tubo do aparelho de raios- $x$

Figura 4.7- Conjunto posicionador - registro oclusal - filme e anel de resina colocados em posição no ato da tomada radiográfica.

Figura 4.8- Reveladora automática utilizada no momento da revelação das películas radiográficas.

Figura 4.9- Escaner utilizado para a digitalização das películas radiográficas.......40

Figura 4.10- Tela radiográfica com quadrados de 2 × 2 mm .41

Figura 4.11- Exemplo das mensurações utilizando-se o programa Axio-Vision.......42 


\section{LISTA DE TABELAS}

Tabela 4.1 - Tempos de exposição pré-definidos no aparelho de raios-x 39

Tabela 5.1 - Média, mediana, desvio padrão e comparação dos grupos experimentais em relação à JEC-CO. 44

Tabela 5.2- Média, mediana, desvio padrão e comparação dos grupos experimentais em relação à JEC-FD

Tabela 5.3- Porcentagens de mudança óssea dos grupos do estudo em relação às medidas JEC-CO e JEC-FD. 45 


\title{
LISTA DE ABREVIATURAS E SIGLAS
}

\author{
AP ápice radicular \\ CADIA análise densitométrica de imagens auxiliada por computador \\ CEP comitê de ética em pesquisa \\ CO crista óssea \\ DP desvio padrão \\ EDTA ácido etilenodiaminotetracético \\ e-PTFE politetrafluoretileno expandido \\ FAPESP Fundação de amparo à pesquisa do Estado de São Paulo \\ FD fundo do defeito
}

FOUSP Faculdade de Odontologia da Universidade de São Paulo

Gl gengiva inserida

IG índice gengival

IP índice de placa

JEC junção esmalte-cemento

MD mobilidade dental

MO porcentagem de mudança óssea

$\mathrm{NCl}$ nível clínico de inserção

NCIR nível clínico de inserção relativo

PCS profundidade clínica de sondagem

PME proteína da matriz do esmalte

RACR raspagem e alisamento coronário radicular

RET retalho de espessura total 
RG retração gengival

$\mathrm{ROI}$ região de interesse

RTG regeneração tecidual guiada

RVG RadioVisioGraphy

SR superfície radicular

SRD subtração radiográfica digital 


\title{
LISTA DE SÍMBOLOS
}

\author{
- grau \\ $\% \quad$ por cento \\ (B) marca registrada \\ $\mathrm{N}$ número da amostra \\ $>$ maior \\ $\geq \quad$ maior ou igual \\ $\leq \quad$ menor ou igual \\ A Amper \\ $\mathrm{Hz} \quad$ Hertz \\ kV kilovolts \\ $\mathrm{mA}$ miliamper \\ mg miligrama \\ mm milímetros \\ $\mathrm{mm}^{2}$ milímetros quadrados \\ S segundos \\ V volts
}




\section{SUMÁRIO}

1 INTRODUÇÃO

2 REVISÃO DA LITERATURA

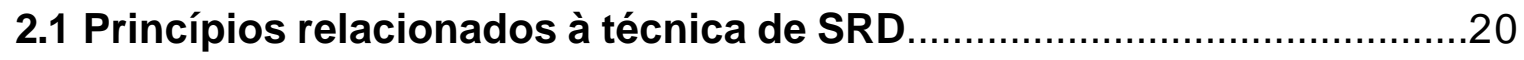

2.2 Aplicação da SRD em Periodontia ....................................................25

2.3 Ensaios clínicos - SRD e Regeneração periodontal.............................27

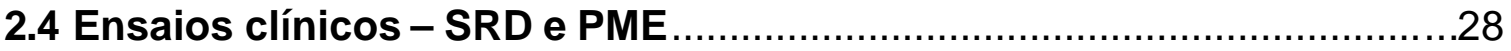

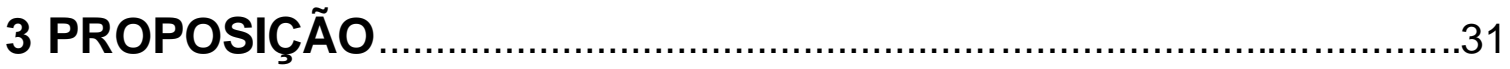

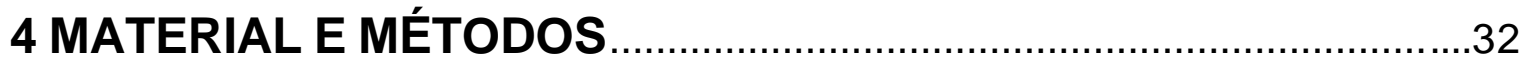

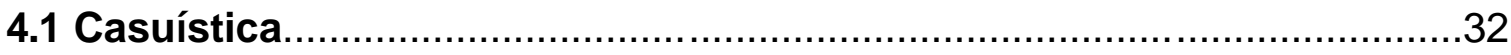

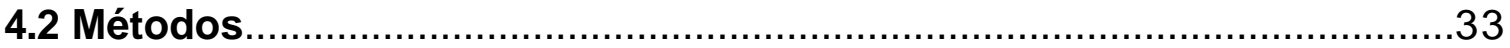

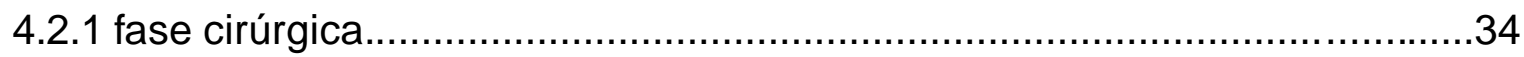

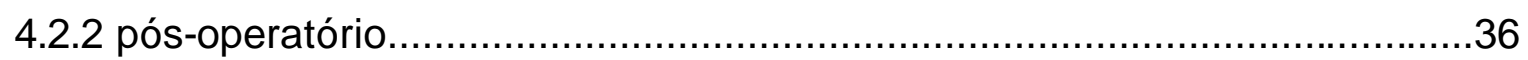

4.2.3 padronização das imagens radiográficas.............................................36

4.2.4 processo de mensuração das imagens.................................................40

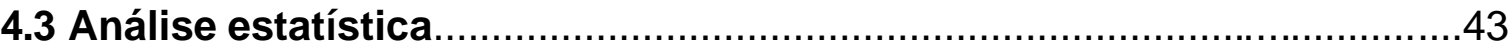

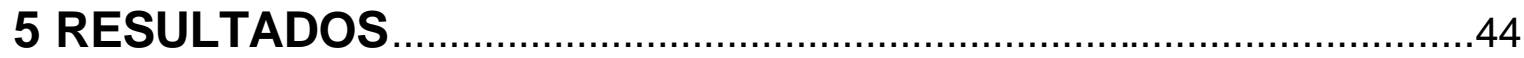

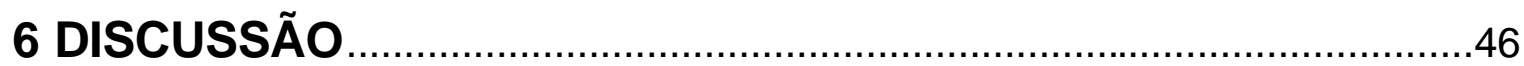

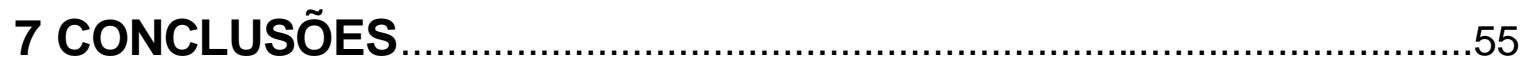

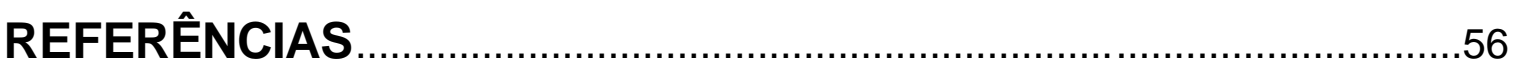

ANEXOS 


\section{INTRODUÇÃO}

Usualmente, o monitoramento da doença periodontal é feito utilizando-se o Nível Clínico de Inserção (NCl) como parâmetro clínico e as radiografias periapicais como auxiliares neste processo. Todavia, sabe-se que estes métodos de diagnóstico não são precisos. Deste modo, a subtração radiográfica digital (SRD) tem sido utilizada na tentativa de minimizar erros de diagnóstico e torná-lo mais preciso. Em 1935, Ziesdses des Plantes definiu subtração radiográfica como "a diferença entre duas radiografias tiradas antes e depois da injeção de contraste na arteriografia", porém sua aplicação na odontologia e sua transformação para padrões digitais só foram conseguidas por Ando et al. (1968,1969). Gröndahl; Gröndahl e Webber (1983) expuseram os conceitos básicos da técnica, mostrando que a visualização da imagem depende diretamente do contraste e das estruturas circunjacentes. Afirmaram também que projeções idênticas, ou praticamente idênticas, são indispensáveis para a obtenção de imagens subtraídas e, por fim, que distorções originadas por pequenas diferenças de angulação no ato da tomada radiográfica influenciam a precisão de diagnóstico. Webber, Ruttimann e Gröndahl (1982), revisando a literatura, ressaltaram a necessidade de se anular as estruturas anatômicas imutáveis, além de se equilibrar o contraste e os níveis de cinza nas imagens digitalizadas.

Ainda na década de 80 , foi demonstrado que a SRD permitia a detecção de mudanças ínfimas da crista óssea alveolar de forma mais precisa que o método de sondagem, embora estas técnicas avaliem diferentes áreas do periodonto (HAUSMANN et al., 1985b, 1986). Validou-se também o método como o mais efetivo 
na quantificação e na precisão de diagnóstico de mudanças ósseas em estudos clínicos periodontais (BRÄGGER et al., 1988; GRÖNDAHL; GRÖNDAHL, 1983; RETHMAN et al., 1985a).

A SRD permite a detecção de mudanças ósseas com um erro médio de até 0,15 mm (JEFFCOAT; JEFFCOAT; WILLIAMS, 1984), de reabsorções ósseas de menos de 0,1 mm (JEFFCOAT; WANG; REDDY, 1995) e apresenta altas taxas de sensibilidade $(94,4 \%)$ e especificidade $(97,7 \%)$ (JEFFCOAT, 1992). Programas de computador ainda estão sendo desenvolvidos para minimizar erros inerentes à técnica. Um destes programas é o sistema de análise densitométrica de imagens auxiliada por computador (CADIA), que é capaz de eliminar a distorção e ajustar o contraste das imagens (BRÄGGER, 1988).

Diversos autores concordam que a SRD melhora a precisão de diagnóstico de pequenas mudanças ósseas em comparação ao método convencional (BYRD et al.,1998; GRÖNDAHL et al., 1987; JEFFCOAT; WANG; REDDY, 1995; KULLENDORFF et al., 1988, 1992). A seleção de regiões de interesse (ROI) e sua respectiva coloração melhoraram de forma eficaz a concordância entre diferentes examinadores (BRÄGGER et al., 1994; BRÄGGER; PASQUALI, 1989; REDDY et al., 1991). Além disso, a SRD serviu como um método auxiliar na avaliação da técnica de regeneração tecidual guiada (RTG) em estudos clínicos de furca graus II e III e defeitos infra-ósseos (CHAVES et al., 1996; CHRISTGAU et al., 1995, 1996, 2002; DUBREZ; DUROUX; CIMASONI, 1996; EICKHOLZ; HAUSMANN, 1997, 1998, 1999).

Tratando-se da proteína derivada da matriz do esmalte (PME), foi observado que há poucos trabalhos (HEIJL et al.,1997; OKUDA et al., 2000; PARASHIS; TSIKLAKIS, 2000; PIETRUSKA, 2001; WINDISCH et al., 2002, FRANCETTI et al., 
2004) que utilizaram também o exame radiográfico como forma de avaliação do efeito regenerativo deste material. Além disso, Esposito, Coulthard e Worthington (2005) revelaram em sua revisão sistemática que apenas Heijl et al. (1997) utilizaram uma metodologia de mensuração radiográfica válida até o momento. E, por fim, Graves (1997) e Reddy (1997) salientaram que, o NCl associado à SRD, são os principais métodos avaliativos de procedimentos regenerativos em ensaios clínicos, justificando-se assim a realização deste trabalho. 


\section{REVISÃO DA LITERATURA}

\subsection{Princípios relacionados à técnica de SRD}

Dentre os vários requisitos básicos da técnica, a padronização da tomada radiográfica é de suma importância. Portanto, conseguir projeções geométricas idênticas ou quase idênticas, torna-se essencial (GRÖNDAHL, H; GRÖNDAHL, K; WEBBER,1983), caso contrário a inexata projeção geométrica dos raios-x leva à introdução de artefatos que prejudicam o resultado final da imagem subtraída (WEBBER; RUTTIMANN; GRÖNDAHL, 1982). Existem dois métodos de aquisição de radiografias padronizadas: o cefalostato e os posicionadores associados a registros oclusais.

Jeffcoat et al. (1985) utilizaram pela primeira vez o cefalostato em seis pacientes, com um ângulo de exposição de $60^{\circ}$, tempo de exposição de $1 \mathrm{~s}$, potência de $90 \mathrm{kV}$ e $15 \mathrm{~mA}$. A nova técnica foi comparada a dos posicionadores resultando no sucesso da subtração das imagens e, principalmente, na diminuição da radiação. Em outro estudo, Jeffcoat et al. (1987), comparando novamente as duas técnicas, observaram que o valor médio de diferença angular foi de $0,33^{\circ}$, sendo $1,5^{\circ}$ o maior valor encontrado, o que resultou na superioridade da técnica do cefalostato. Em contra partida, Zappa et al. (1991) obtiveram os menores resultados de erros de angulação já descritos na literatura através de um novo sistema de posicionador associado ao registro oclusal. As exposições foram de 0,5 s sob uma potência de $65 \mathrm{kV}$ e 7,5 mA, sendo a maior variação angular registrada de $-0,11^{\circ}$. 
Zappa et al. (1993) avaliaram a longo prazo (0, 6, 12 meses) os erros angulares verticais, horizontais e oblíquos relativos à técnica descrita em 1991, não observando mudanças significativas.

Mesmo assim, o deslocamento vertical de apenas $0,1 \mathrm{~mm}$ parece produzir o maior efeito de falsos ganhos ou perdas de osso (37\%), seguido do deslocamento oblíquo (34\%) (BENN, 1990). Em contra partida, Jeffcoat, Jeffcoat e Williams (1984), em um estudo realizado em cães, observaram que para as angulações que variaram menos de 0,2 mm não havia diferença estatisticamente significante na mensuração da quantidade de perda óssea.

Apesar da utilização da técnica do posicionador associado aos registros oclusais ser mais comumente utilizada, por sofrer distorções, o material utilizado para a confecção do registro pode influenciar a padronização. A resina acrílica parece ser o material de eleição (BRÄGGER et al., 1987, 1988, 1998; CHRISTGAU et al, 1995, 1996; GRIFFTHS et al., 1996; HAUSMANN et al., 1986; NICOPOULOUKARAYIANNI et al., 1991; PUTININS; LAVELLE; HOTHVIS, 1988; RETHMAN et al., 1985a; YOUNG et al., 1996; ZAPPA et al., 1991, 1993), entretanto, a utilização de outros materiais tem sido apresentada na literatura, como por exemplo, a silicona (Regisil) (RAWLINSON; ELLWOOD; DAVIES, 1999) e o poliéter (Polyjel) (SCHMIDT; LOESCHE; WEBBER, 1985; SCHMIDT et al.,1988). Em relação aos erros de angulação horizontal e vertical o Regisil mostrou-se como o mais confiável, seguido do Polyjel e da resina acrílica Duralay (RUDOLPH; WHITE, 1988).

Além da dificuldade de padronização das imagens, as variações não controladas de espessura e processamento dos filmes, as mudanças resultantes do crescimento e desenvolvimento normal dos tecidos (WEBBER; RUTTIMANN; GRÖNDAHL, 1982) e os procedimentos de digitalização, levam a diferenças nos 
tons de cinza, significando que a SRD necessita da normalização das imagens (LEHMANN; GRÖNDAHL; BENN, 2000). Em relação à digitalização, a composição da imagem é traduzida por bits (dígitos binários), formada por linhas e colunas, chamada de matriz. Cada ponto desta matriz é denominado de pixel (elemento de imagem) e quanto menor seu tamanho maior a resolução da imagem, sendo usual a utilização de 512 X 512 pixels, o que traduz um tamanho de pixel aproximado de 0,08 mm (WENZEL, 1991).

De modo geral, todos estes aspectos promovem artefatos que necessitam ser diminuídos ou eliminados. Todas as técnicas que tentam reduzi-los são baseadas na teoria de que a visualização radiográfica da lesão depende diretamente de seu contraste e inversamente da complexidade das estruturas circunvizinhas (GRÖNDAHL, H; GRÖNDAHL, K; WEBBER,1983; PUTNINS; LAVELLE; HOTHVIS, 1988), ou ainda, que todas as estruturas anatômicas que ocultam o local de interesse na imagem radiográfica são chamadas de ruídos de estrutura (WENZEL, 1991). Assim, o dente, o espaço do ligamento periodontal e o osso alveolar apresentam diferentes densidades para o sistema CADIA ou quaisquer outros sistemas. Com o objetivo de eliminar a chance de diagnósticos falso-positivos, valores limites devem ser determinados antes da subtração das imagens, indepentendemente do sistema utilizado (BRÄGGER et al., 1998; STEFFENSEN et al., 1989). Porém, quando o sistema CADIA é usado comparando quantitativamente diferentes tipos de sítios (com perda óssea x sem perda óssea), recomenda-se a seleção da ROI com tamanho e localização semelhantes (STEFFENSEN et al., 1991).

Rudolph, White e Mankovich (1985) mostraram que os tempos de exposição $(0,61 \mathrm{~s})$ e potência $(70 \mathrm{kV})$ utilizadas na clínica diária poderiam ser empregados na 
técnica de SRD. Além disso, a utilização do mesmo tipo de filme, tempo de exposição e potência levaria à equalização do contraste e da densidade, respectivamente (HARDSTEDT; WELANDER, 1974).

Com relação ao contraste, interpretado por uma escala de tons de cinza de 0 a 256 (ANDO et al., 1969), a correção pode ser obtida pela distribuição direta dos níveis de cinza (LEHMANN; GRÖNDAHL; BENN, 2000) através de um algoritmo não-paramétrico que corrige o contraste das imagens antes da subtração, obtendose maior homogeneidade dos histogramas de cinza (RUTTIMANN et al., 1986). Outra maneira de ajustar o contraste refere-se à confecção de cunhas feitas a base de diferentes camadas de papel laminado de 0,025 mm de espessura (PUTNINS; LAVELLE; HOTHVIS, 1988), de folhas de cobre de 0,05 mm (DUCKWORTH et al., 1983) ou de alumínio (RUTTIMANN; WEBBER, 1987; WEBBER; RUTTIMANN; HEAVEN,1990; ALLEN; HAUSMANN, 1996) que são colocadas diretamente no filme ou no posicionador. Esta técnica é classificada como indireta e apresenta como principal vantagem a normalização absoluta das imagens por permitir mensurações quantitativas, tais como, mudanças do volume ósseo (LEHMANN; GRÖNDAHL; BENN, 2000). A calibração é feita eliminando-se a falta de homogeneidade entre as imagens a partir da comparação dos valores de pixels das estruturas anatômicas de interesse com os da cunha de alumínio (VOS et al., 1986).

A cunha pode ser colocada em cada uma das radiografias, em seguida a calibração é feita em cada uma delas e depois se subtrai as imagens, ou ainda, se utiliza apenas uma cunha na radiografia inicial, sendo o cálculo realizado na imagem subtraída (WEBBER; RUTTIMANN; HEAVEN, 1990). Todavia, a técnica de utilização de duas cunhas mostrourse mais precisa para estimar o volume de lesões, quando comparada ao método de uma cunha, mostrando valores de correlação 
entre 45-70\% e 28-51\%, respectivamente (ALLEN; HAUSMANN, 1996). Além disso, este tipo de técnica permitiu estimar o volume de crescimento ósseo ao se utilizar o peso conhecido de fragmentos ósseos, obtendo-se um valor de correlação igual a 93\% $\left(r^{2}=0,93\right)$ (RUTTIMANN; WEBBER, 1987).

Outro ponto importante da técnica refere-se ao alinhamento das imagens que Lehmann; Gröndahl e Benn (2000) classificaram como manual, semi-automático e automático. Tradicionalmente, os pares radiográficos eram alinhados manualmente e a diferença entre as imagens era mostrada no monitor (BYRD et al., 1998). Com o desenvolvimento de algoritmos, o alinhamento entre as imagens tornou-se possível através da marcação de pontos de referência como a junção cemento-esmalte (JEC), o ápice radicular (AP) e a crista óssea (CO) (BYRD et al, 1998; JEFFCOAT; JEFFCOAT; WILLAMS, 1984). A escolha de pontos de referência mostrourse superior ao método manual, independentemente da angulação utilizada $\left(0^{\circ}\right.$ a $\left.10^{\circ}\right)$, tornando as imagens mais homogêneas (WENZEL, 1989). Além disso, a seleção de 3 e 4 pontos no modelo semi-automático mostrou altos índices de sensibilidade (89\% e $100 \%)$ e especificidade (100\% e 100\%), respectivamente, mantendo a eficácia de diagnóstico para lesões de menos de 10 mg (BYRD et al., 1998).

Yonn (2000) comparou um novo programa de alinhamento, desenvolvido no departamento de Radiologia da Universidade da Califórnia (Visual Basic GUI), com o programa Emago v. 2.01 que utiliza 4 pontos de referência anatômica marcados com o mouse. Foram analisados oito pares radiográficos obtidos com a técnica do cefalostato. Os resultados deste estudo revelaram que o novo método era três vezes mais rápido do que o sistema utilizado pelo programa Emago. 


\subsection{Aplicação da SRD em Periodontia}

A SRD mostrou ser capaz de exibir a extensão da atividade da doença em pacientes com periodontite sem tratamento e sob monitoramento por seis meses (HAUSMANN et al., 1985a). Quando comparada aos parâmetros clínicos (índice de placa (IP), índice gengival (IG) e profundidade clínica de sondagem (PCS)) apenas os sítios com PCS $>7 \mathrm{~mm}$ apresentaram perda óssea, sugerindo que tais parâmetros tinham valores preditivos baixos para determinar atividade de doença em comparação com a SRD (HAUSMANN et al., 1986). O monitoramento de indivíduos saudáveis por três anos, utilizando a SRD nas mesmas regiões, melhorou a reprodutibilidade das imagens e permitiu o diagnóstico precoce de lesões periodontais (GRIFFITHS et al., 1996).

Os efeitos do tratamento periodontal também têm sido avaliados e expostos na literatura. Por exemplo, macacos Rhesus submetidos à raspagem e aplainamento coronário radicular (RACR) e mantidos em controle por 40 dias, apresentaram aumento da radiodensidade nas cristas ósseas alveolares em comparação ao grupo controle (RETHMAN et al., 1985b). Por outro lado, estudos que utilizaram procedimentos cirúrgicos como coadjuvante ao tratamento convencional mostraram perda óssea em $21 \%$ dos sítios (SCHMIDT et al., 1988). Observou-se também que o método mesmo apresentando $69,5 \%$ dos sítios com perda óssea pôde ser considerado não invasivo e quantitativo para o acompanhamento de mudanças ósseas (BRÄGGER et al., 1987).

Ao revisarem a técnica de obtenção do volume das lesões ósseas, Ruttiman e Webber (1987) expuseram que ele é estimado pelo produto da ROI e a diferença 
média do nível de cinza entre a lesão e a região ao seu redor. Este sistema mostrouse quantitativo e preciso para a utilização em estudos longitudinais, uma vez que o erro médio proporcional ao da área estudada é de $0,054 \mathrm{~mm}^{2} / \mathrm{mm}^{2}$ (VOS et al., 1986). Isto significa que mudanças muito pequenas na massa de cálcio podem ser detectadas pela SRD, variando de 0,1 a 0,15 mg (CHRISTGAU et al., 1998). Em acordo com esta afirmação, um estudo multicentro concluiu que a SRD é válida, pois altas taxas de sensibilidade (87,7\%) e especificidade (100\%) foram conseguidas para mudanças ósseas simuladas de 1, 7 e $10 \mathrm{mg}$ (JEFFCOAT et al., 1996). Por fim, a SRD seria aplicável para investigações de pequenas mudanças ósseas, para diagnóstico e monitoramento das formas destrutivas de doença periodontal (RAWLINSON; ELLWOOD; DAVIES, 1999), assim como procedimentos regenerativos, uma vez que foi sugerida a associação dos parâmetros clínicos com a SRD em ensaios clínicos (REDDY, 1997; REDDY, 1997).

No que se refere à avaliação da precisão de diagnóstico de lesões ósseas, a literatura mostrou melhora na visualização e detecção de lesões induzidas em comparação ao método convencional, como também aumento na precisão de diagnóstico (GRÖNDAHL; GRÖNDAHL 1983), redução do tempo gasto para realizálo (RETHMAN et al., 1985a) e uma maior taxa de concordância intra-examinador $(73,8 \%)$ e inter-examinador $(60,5 \%)$, quando comparada ao método convencional, $60,9 \%$ e 38,3\%, respectivamente (GRÖNDAHL et al., 1987). Segundo Brägger e Pasquali (1989) e Reddy et al (1991) a utilização de cores nas imagens subtraídas aumentou a concordância inter e intra-examinadores.

De fato, a coloração e aumento de contraste nas imagens não só aumentou a concordância de diagnóstico de mudanças ósseas (BRÄGGER et al., 1994), como 
também possibilitou a melhor detecção de lesões de 0,5 mm, em especial na região de pré-molares (PUTNINS; LAVELLE; HOTHVIS, 1988).

Independentemente do tipo de filme utilizado (Ultra-Speed e Ektaspeed) a SRD melhorou o desempenho dos examinadores para diagnosticar lesões induzidas (0,5 a 1,1 mm de diâmetro) (NICOPOULOU-KARAYIANNI et al., 1991), em especial para pequenas lesões localizadas na região periapical (KULLENDORF et al., 1988), sendo as lesões inter-radiculares de maior dificuldade de detecção (KULLENDORF et al., 1992).

\subsection{Ensaios clínicos - SRD e Regeneração periodontal}

Vários autores têm avaliado a regeneração de defeitos infra-ósseos interproximais e de envolvimentos de furca através da SRD (CHAVES et al., 1996; CHRISTGAU et al., 1995, 1996, 2002; DUBREZ; DUROUX; CIMASONI, 1996; EICKHOLZ; HAUSMANN, 1997, 1998, 1999). Dentre estes autores, alguns tentaram correlacionar os parâmetros clínicos ( $\mathrm{NCl}$ vertical e horizontal e JEC ao fundo do defeito (FD)) com os radiográficos, através da análise de regressão linear (CHRISTGAU et al., 1996; EICKHOLZ; HAUSMANN, 1997, 1998, 1999). Dentre estes estudos, Christgau et al. (1996) e Eickholz e Hausmann (1998) não encontraram correlação entre os parâmetros clínicos e a mensuração radiográfica linear, enquanto que Eickholz e Hausmann (1998) não acharam correlação para os valores densitométricos (valores que mensuram a área ou o volume de ganho ou perda óssea), sugerindo que os dois parâmetros deveriam ser utilizados. 
Por outro lado, foi encontrada correlação positiva entre os $\mathrm{NCl}$ vertical e horizontal com a mensuração radiográfica linear (EICKHOLZ; HAUSMANN, 1997) e com os valores densitométricos (EICKHOLZ; HAUSMANN, 1999), ao utilizarem membranas absorvíveis (Polyglactin-910) e não-absorvíveis (politetrafluoretileno expandido - e-PTFE) em defeitos de furca grau II e III. Em 30 defeitos infra-ósseos também foi encontrada correlação positiva entre os parâmetros clínicos e os valores densitométricos após o período de 13 meses (CHRISTGAU et al., 1996).

A comparação entre membranas absorvíveis (Polyglactin-910) e nãoabsorvíveis (e-PTFE) na regeneração de defeitos de furca e defeitos infra-ósseos não mostrou diferença estatisticamente significante em relação aos parâmetros clínicos e radiográficos (CHRISTGAU et al., 1995).

Quando se comparou a RTG versus o retalho de espessura total (RET) para o tratamento de envolvimentos furca grau II (CHAVES et al., 1996; DUBREZ; DUROUX; CIMASONI, 1996) e defeitos infra-ósseos (CHAVES et al., 1996) a avaliação radiográfica não mostrou diferenças estatisticamente significantes para a mensuração linear (DUBREZ; DUROUX; CIMASONI, 1996). Ao se avaliar a quantidade de massa óssea neoformada, o grupo tratado com a membrana Guidor demonstrou diferença estatisticamente significante (CHAVES et al., 1996).

\subsection{Ensaios clínicos - SRD e PME}

O levantamento bibliográfico revelou 6 estudos que utilizaram a também a avaliação radiográfica do efeito da $\mathrm{PME}$ em defeitos infra-ósseos além do $\mathrm{NCl}$. 
Quatro deles utilizaram a técnica de SRD linear (HEIJL et al., 1997; PARASHIS; TSIKLAKIS, 2000; WINDISCH et al, 2002; FRANCETTI et al., 2004), um calculou as diferenças entre o teste e o controle através da densidade óssea (OKUDA et al., 2000) e um não utilizou a técnica de SRD (PIETRUSKA, 2001).

Em relação aos pontos de referência para a mensuração linear, a JEC serviu como referencial para as distâncias até a CO e o FD (PARASHIS; TSIKLAKIS, 2000; WINDISCH et al, 2002), servindo como parâmetros de medida de ganho ou perda óssea em relação ao defeito, enquanto que Heijl et al (1997) utilizaram para esta avaliação a distância do AP ao FD. Além disso, Heijl et al (1997) consideraram como perda óssea inicial a distância do ponto localizado $1 \mathrm{~mm}$ apicalmente à JEC até o FD.

Após 6 meses não foi observada diferença estatística entre a utilização da RTG versus a PME para as medidas da JEC - CO (RTG: 0,40 mm; PME: 0,33 mm) e da JEC - FD (RTG: 0,47 mm; PME: 1,05 mm) (WINDISCH et al, 2002), assim como, após 1 ano de tratamento (RTG: 2,3 mm; PME: 2,6 mm) (PIETRUSKA, 2001). Baseado em parâmetros de mensuração linear foi possível observar após 1 ano do tratamento com a PME um ganho ósseo médio de $61 \%$ (23-88\%), considerando-se uma reabsorção média da CO de 20,7\% (PARASHIS; TSIKLAKIS, 2000), após 2 anos houve um preenchimento médio do defeito de 57\% (FRANCETTI et al., 2004), enquanto que após 3 anos estes ganhos chegaram em média a $66 \%$ ou 2,7 mm (HEIJL et al., 1997).

Okuda et al (2000) utilizaram o sistema Digora para a aquisição das imagens e o programa NIH image public domain versão 6.1 para a realização da subtração das imagens de defeitos infra-ósseos tratados com PME ou apenas o veículo (Alginato propileno glicol). Desta forma, foi observado após 1 ano um ganho médio 
de densidade óssea de $20,2 \pm 16,6 \%$ para o grupo teste em comparação a apenas $3,94 \pm 23,3 \%$ para o grupo controle. No estudo de Parashis e Tsiklakis (2000) também foi realizada a subtração das imagens, obtida pelo programa Emago / Advanced v 3.1 (Oral Diagnostic Systems, Amsterdam, Holanda), porém nenhum sistema de padronização das imagens foi utilizado, a não ser o alinhamento das imagens pela seleção de 4 pontos de referência anatômica. 


\section{PROPOSIÇÃO}

Verificar, comparativamente, através da SRD linear o efeito do tratamento de defeitos infra-ósseos de 2 ou 3 parede por meio do retalho de espessura total reposto associado ou não à proteína derivada da matriz do esmalte . 


\section{MATERIAL E MÉTODOS}

Este estudo foi aprovado pelo CEP da FOUSP sob a forma de um novo protocolo de pesquisa (Anexo A) e contou com o auxílio financeiro da Fundação de Amparo à Pesquisa do Estado de São Paulo (FAPESP) cujo projeto foi o de $n^{\circ}$ 00/12285-0.

\subsection{Casuística}

A seleção da amostra foi realizada na clínica de Pós-graduação da FOUSP e seguiu critérios de inclusão e exclusão pré-estabelecidos que serviram como requisitos para a participação dos sujeitos da pesquisa. Os critérios de inclusão foram:

1. Idade acima de 25 anos;

2. Periodontite crônica (ARMITAGE, 1999);

3. Boa saúde geral;

4. Dois ou mais defeitos infra-ósseos de 2 ou 3 paredes em dentes unirradiculares com profundidade clínica de sondagem (PCS) $\geq 5 \mathrm{~mm}$, após os procedimentos básicos;

5. Índice de placa $\leq 20 \%$;

6. Gengiva inserida $\geq 2 \mathrm{~mm}$.

Os critérios de exclusão foram: 
1. Antibioticoterapia seis meses antes do tratamento;

2. Tratamento endodôntico nos dentes com de defeito(s) infra-ósseo(s);

3. Mobilidade grau 3 (O'LEARY; RUDD, 1963).

A partir destes critérios foram selecionados 11 sujeitos, os quais apresentaram pelo menos 2 ou mais defeitos, totalizando 45 defeitos.

\subsection{Métodos}

Todos os participantes responderam a um questionário sobre sua saúde geral, hábitos e história dental. O termo de consentimento livre e esclarecido (Anexo B) foi apresentado a cada um deles e assinado, quando o indivíduo estava de pleno acordo com as condições expostas.

Todos os indivíduos foram submetidos às instruções de higiene bucal, raspagem e alisamento coronário radicular (RACR) com instrumentos manuais e, se necessário, ajustes oclusais. Todos os sujeitos foram reavaliados após um período de 4 a 6 semanas e, neste momento, definiram-se as áreas cirúrgicas. Deste momento em diante foram obtidos dados clínicos, radiográficos e fotografias das regiões escolhidas. Os dados clínicos foram obtidos no início, trans-cirúrgico, 6 e 12 meses, enquanto que as radiografias foram executadas no início e aos 12 meses, de acordo com os métodos que serão expostos posteriormente.

Um único examinador cego (D.C.) para o código dos tratamentos coletou todos os parâmetros clínicos, tendo sido obtida anteriormente a calibração intra- 
examinador para o Nível Clínico de Inserção Relativo (NICR) (REDDY, 1997), cuja reprodutibilidade foi averiguada através do coeficiente de correlação intra-classe $(0,98)$ (KIRKWOOD, 1988). Os parâmetros clínicos averiguados foram:

1. Índice gengival (IG) (LÖE, 1967);

2. Índice de Placa (IP) (SIL NESS; LÖE, 1964);

3. Profundidade clínica de sondagem (PCS);

4. Nível clínico de inserção relativo $(\mathrm{NCR})$;

5. Retração gengival (RG);

6. Largura de faixa de gengiva inserida (GI);

7. Mobilidade dental (MD) (O'LEARY; RUDDY, 1963).

Para a obtenção dos parâmetros clínicos foram confeccionadas guis individualizadas de resina acrílica. Para os parâmetros IG, IP, PCS, RG, GI utilizouse uma sonda milimetrada convencional (PCP-UNC, Hu-friedy®, Chicago, IL, USA). Para o NCIR foi utilizada uma sonda computadorizada (Florida Probe®, Florida Probe Corporation, Gainnesville, Florida, USA).

\subsection{1 fase cirúrgica}

Apenas um pesquisador (M.C.C.) realizou as cirurgias na ausência do examinador (D.C.). O estudo recebeu delineamento de boca dividida, pois todos os sujeitos da pesquisa apresentaram 2 ou mais defeitos, consequentemente, o indivíduo era seu próprio controle. Os defeitos foram distribuídos em dois grupos distintos, de maneira aleatória, através de sorteio com moeda. O grupo teste 
caracterizou-se por associar o retalho de espessura total reposto (RET) com a PME (Emdogain $^{\circledR}$, Biora AB, Malmö, Sweden), sendo denominado de PME (22 defeitos), enquanto que o grupo controle (23 defeitos) recebeu apenas o retalho de espessura total reposto para debridamento e foi chamado de grupo RET.

No momento trans-cirúrgico os defeitos infra-ósseos foram fotografados e realizoutse a mensuração de suas dimensões com uma sonda periodontal convencional (PCP-UNC, Hu-friedy®, Chicago, IL, USA). Tais medidas foram:

1. Distância da junção esmalte-cemento à crista óssea alveolar (JEC-CO);

2. Distância da crista óssea alveolar ao fundo do defeito (CO-FD), caracterizando o componente vertical do defeito infra-ósseo;

3. Distância da crista óssea alveolar à superfície radicular (CO-SR), caracterizando o componente horizontal do defeito;

A aplicação do Emdogain ${ }^{\circledR}$ seguiu as normas do fabricante, significando que a superfície radicular foi previamente condicionada com gel de EDTA a $24 \%$ (Prefgel®, Biora AB, Malmö, Sweden) por dois minutos, lavada com solução salina e seca com sugador e gaze estéril. A colocação da PME começou do fundo do defeito até a JEC. Todas as áreas foram suturadas com fio de nylon 5-0 (Tech-Lon®, TechSynt/Lukens Ind. Com. Imp. e Exp. S/A, São Paulo, SP, Brasil). 


\subsection{2 pós-operatório}

Foi administrado analgésico (Tylenol 750 mg; Cilag Farmacêutica LTDA, São Paulo, SP, Brasil) de 6 em 6 horas somente em caso de dor. O controle do biofilme dental foi realizado através de bochechos com gluconato de clorexidine a $0,12 \%$ (Periogard®, Colgate-Palmolive Divisão Kolynos do Brasil LTDA, Osasco, Brasil) duas vezes ao dia, durante as 4 semanas subseqüentes, após a higiene bucal. Todos os pacientes foram acompanhados semanalmente até a $8^{a}$ semana e em seguida entraram em regime de controle e manutenção a cada 2 meses até completarem 12 meses. Após 1 semana as suturas foram removidas

\subsection{3 padronização das imagens radiográficas}

Para a padronização das imagens radiográficas foi utilizado um posicionador radiográfico para dentes anteriores (Modelo Han-Shin - Indusbello ${ }^{\circledR}$ ). Na extremidade em que se coloca a película radiográfica foram adaptados três pinos para troquel de tal forma que ficassem paralelos entre si (Figura 4.1 e 4.2).

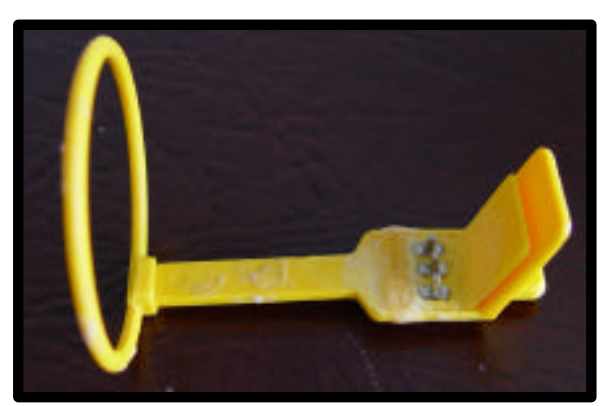

Figura 4.1- Posicionador radiográfico modificado 


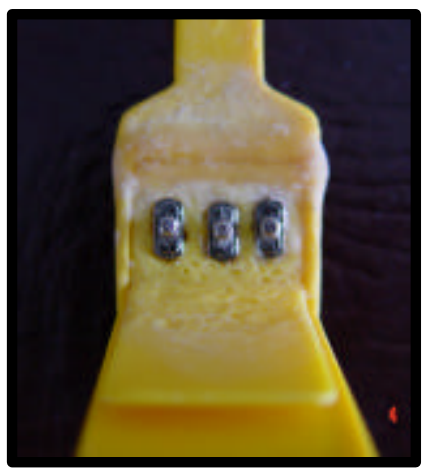

Figura 4.2- Pinos de troquel parelelos entre si

Registros oclusais individualizados foram confeccionados em resina acrílica incolor quimicamente ativada (Jetß, Artigos Odontológicos Clássico LTDA, São Paulo, SP, Brasil) (Figura 4.3). No momento da sua confecção os dentes e o posicionador foram vasilinados. A resina foi manipulada de acordo com as especificações do fabricante e na fase plástica foi levada à boca juntamente com o posicionador, de maneira que o registro dos dentes e dos pinos de troquel ficassem impresso no bloco de resina e estabelecessem uma posição individualizada para cada região (Figura 4.4).
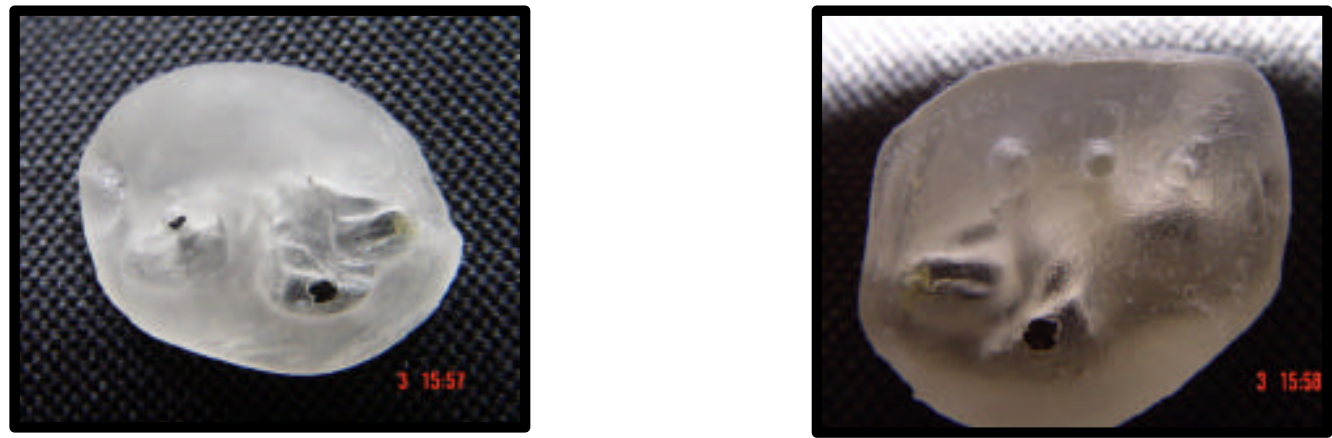

Figura 4.3- Registro oclusal de resina acrílica de uma das regiões a serem operadas

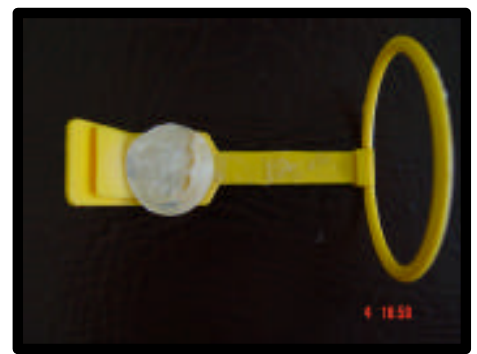

Figura 4.4- Conjunto posicionador - registro oclusal para a padronização das tomadas radiográficas 
Um anel de resina quimicamente ativada (Jet®, Artigos Odontológicos Clássico LTDA, São Paulo, SP, Brasil) foi construído sobre o tubo do aparelho de raios-x (Figura 4.5 e 4.6). Este anel permitiu a colocação do conjunto posicionadorregistro-filme de maneira justaposta ao tubo no momento das tomadas radiográficas, possibilitando que o conjunto retornasse sempre na mesma posição (Figura 4.7). A borda do tubo serviu como referência para o posicionamento do posicionador, sendo o anel de resina apenas o instrumento de manutenção do sistema.

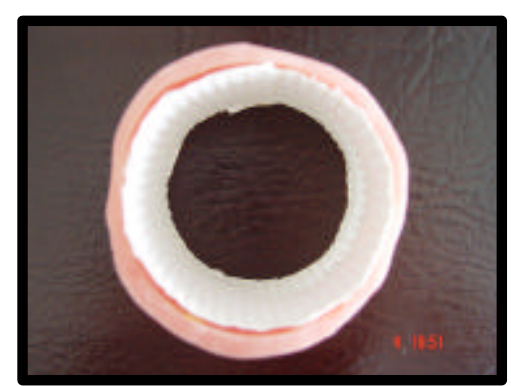

Figura 4.5- Anel de resina acrílica

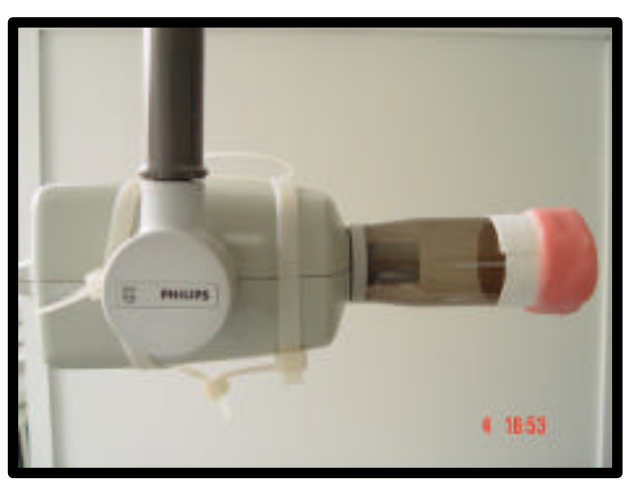

Figura 4.6- Anel de resina acrílica colocado em posição no tubo do aparelho de raios-x

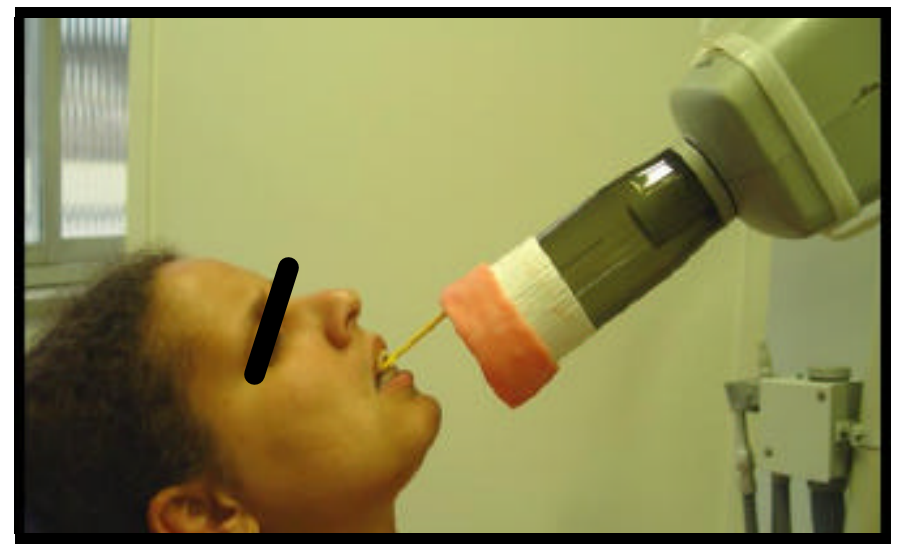

Figura 4.7- Conjunto posicionador - registro oclusal - filme e anel de resina colocados em posição no ato da tomada radiográfica 
A seleção do tempo de exposição foi determinada de acordo com o dente que possuía o defeito, pois o aparelho utilizado (Modelo: ORALIX 65 - PHILIPIS / Tubo: 65 kV / 7,5 mA / Distância focal: = 20 cm / Especificações: 220 V, 4A, 50/60 Hz) dispunha de um sistema semi-automático de seleção de dentes (Incisivos, Caninos, Pré-molares e Molares) com tempos de exposição já estabelecidos, como pode ser observado na tabela abaixo.

Tabela 4.1 - Tempos de exposição pré-definidos no aparelho de raios-x

\begin{tabular}{c|c|c|c}
\hline MANDÍBULA & Segundos & MAXILA & Segundos \\
\hline Molares & $\mathbf{0 , 5 1}$ & Molares & $\mathbf{0 , 8 8}$ \\
\hline Pré-molares & $\mathbf{0 , 4 4}$ & Pré-molares & $\mathbf{0 , 5 9}$ \\
\hline Caninos & $\mathbf{0 , 4 4}$ & Caninos & $\mathbf{0 , 4 4}$ \\
\hline Incisivos & $\mathbf{0 , 4 4}$ & Incisivos & $\mathbf{0 , 5 1}$
\end{tabular}

As películas (Insight $-\operatorname{Kodak}^{\circledR}$ ) com as imagens latentes do início e dos 12 meses foram armazenadas em estojos individualizados em local com ausência de qualquer tipo de luz e/ou umidade. Em cada película foram colocados o nome do paciente, a data de realização da tomada radiográfica e o estágio em que se encontrava o indivíduo no estudo (início ou 12 meses).

Todas as películas foram reveladas no mesmo dia e sob as mesmas condições de temperatura. Para tanto, o processamento foi realizado em uma sala fechada, sendo utilizada uma reveladora automática (A/T 2000 XR - Air Techniques), na qual os líquidos de processamento (revelador e fixador) foram trocados no mesmo dia (Figura 4.8). 


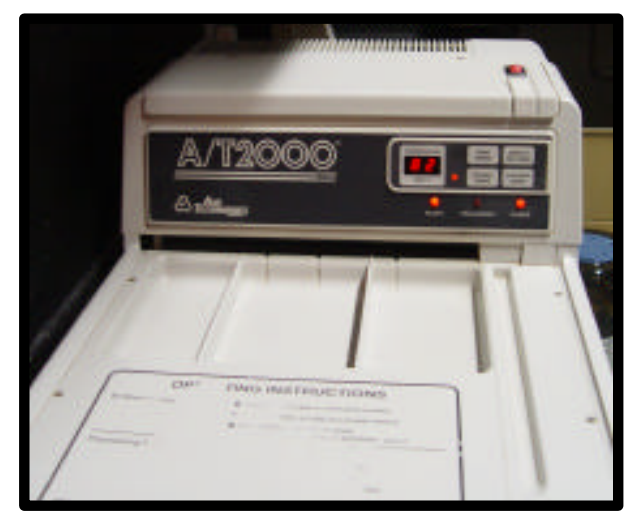

Figura 4.8- Reveladora automática utilizada no momento da revelação das películas radiográficas

\subsection{4 processo de mensuração das imagens}

Todas as radiografias foram digitalizadas pelo mesmo operador (I.M.P.), cego para os grupos de tratamento, em um escaner de slides SprintScan 35 Plus Polaroid) com resolução de 500 dpi e 8 bits (WENZEL, 1991) (Figura 4.9) . Todas as imagens foram gravadas no formato bitmap.

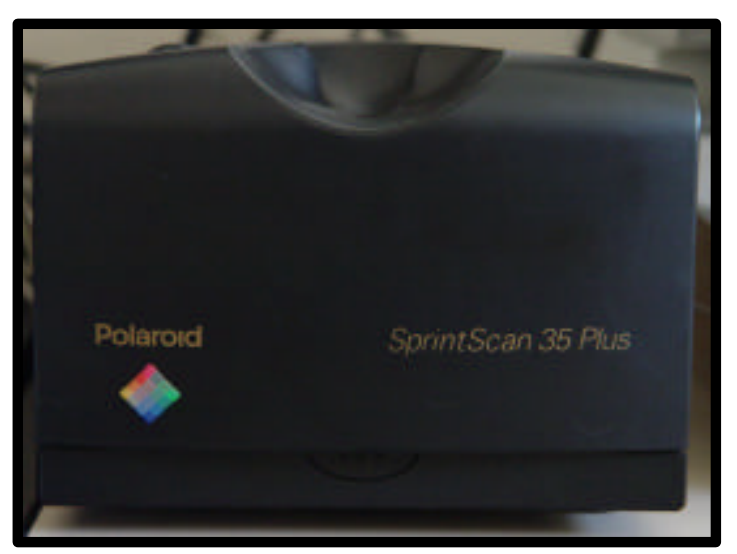

Figura 4.9- Escaner utilizado para a digitalização das películas radiográficas

Foi utilizado para a mensuração linear das imagens o programa de computador Axio-Vision versão 3.0 (Carl Zeiss) que, convencionalmente, é utilizado 
para histometria. Tal programa disponibiliza a criação de escalas de mensuração em diversas unidades de medida. No caso deste estudo, a criação da escala utilizada para a mensuração das imagens foi baseada em uma tela radiográfica cujos quadrados mediam $2 \times 2 \mathrm{~mm}$ cada (Figura 4.10). Esta aferição foi confirmada previamente em diversos pontos da tela com um paquímetro digital.

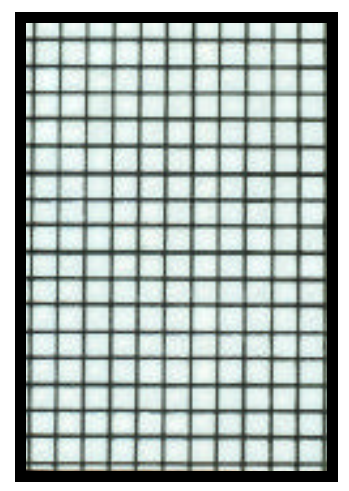

Figura 4.10- Tela radiográfica com quadrados de $2 \times 2 \mathrm{~mm}$

A tela foi escaneada nos mesmos padrões das radiografias e levada ao Axiovision. A partir deste momento foram traçadas duas linhas de referência por cima de um dos quadrados da tela, sendo que uma das linhas foi desenhada na vertical e outra na horizontal. Foi informado ao programa que as linhas mediam $2 \mathrm{~mm}$ cada uma. Desta maneira, uma nova escala de $2 \times 2 \mathrm{~mm}$ foi criada e salva, permitindo a mensuração de distâncias em unidade de milímetros.

A mensuração linear foi padronizada a partir de referências anatômicas estabelecidas de acordo com os seguintes critérios:

1. Distância entre a JEC e a posição mais coronal ao longo da superfície radicular, no qual o espaço do ligamento periodontal aparece normal, caracterizando a porção do fundo do defeito (JEC-FD) (PAPAPANOU; WENNSTRÖM; GRÖNDAHL, 1988);

2. Distância entre a JEC-CO. 
A imagem inicial foi sempre mensurada antes da imagem de 1 ano. Nenhum tipo de ajuste de contraste ou brilho foi realizado. Antes de qualquer marcação do ponto de referência inicial (JEC) a nova escala era aplicada sobre a imagem. No momento da marcação desta referência anatômica as imagens sempre foram magnificadas em 3 vezes, significando que o recurso de zoom era ativado 3 vezes. A partir de cada ponto e com o recurso do zoom ativado foi traçada a linha de mensuração referente à medida desejada, ou seja, JEC-FD, JEC-CO. Todo processo de mensuração também foi realizado por um único examinador (I.M.P.).

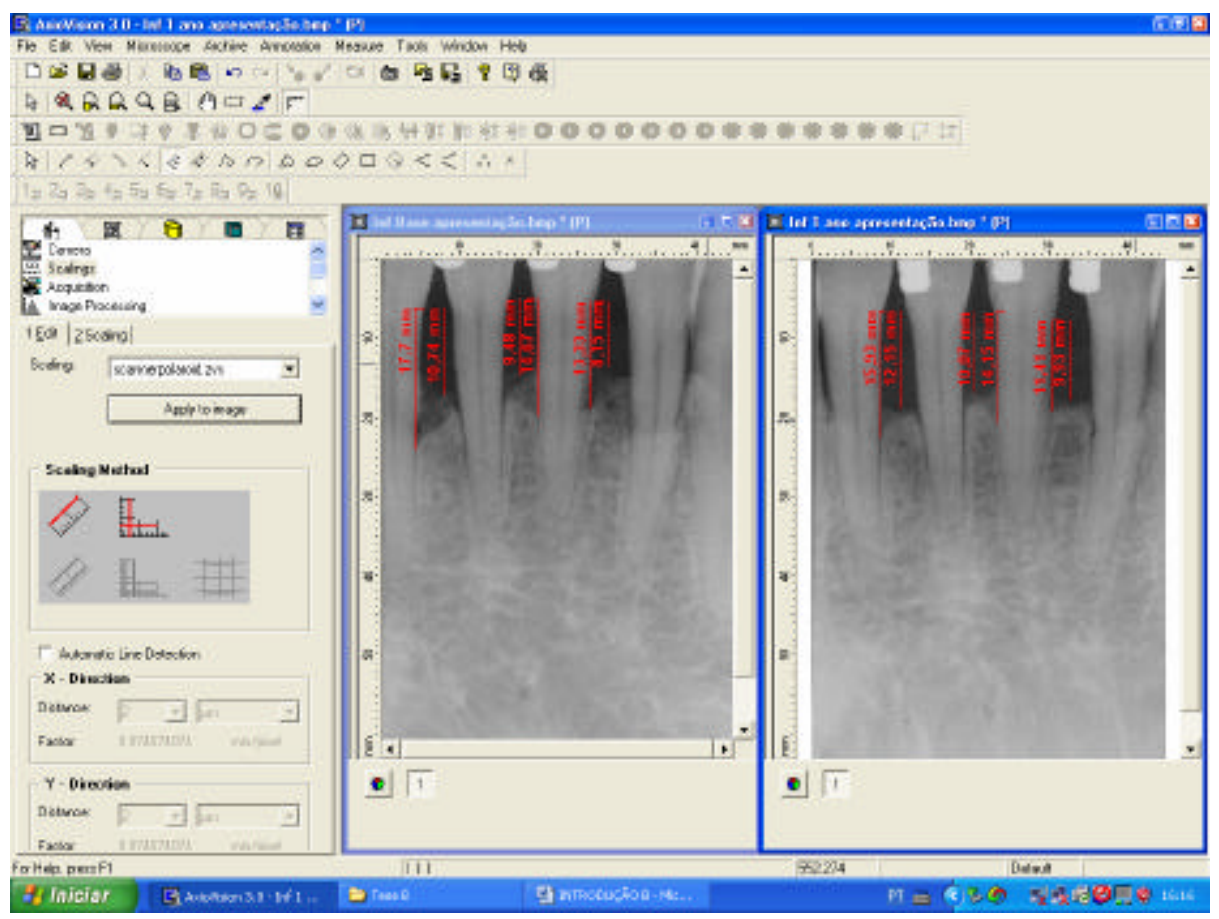

Figura 4.11- Exemplo das mensurações utilizando-se o programa Axio-Vision

Com base nas medidas já mensuradas foram calculadas as porcentagens de mudanças ósseas de acordo com Parashis e Tsiklakis (2000) para cada uma delas. Para tanto, a seguinte fórmula foi empregada:

Inicial - 1 ano

Porcentagem de mudança $=$ $X 100$ (MO) Inicial 


\subsection{Análise estatística}

Como alguns pacientes apresentaram mais do que um defeito de cada grupo experimental foi calculado as médias dos defeitos de grupos de tratamento semelhantes para cada indivíduo. Em seguida, foram calculadas para cada grupo, a média, a mediana e o desvio padrão das variáveis JEC-CO, JEC-FD, utilizando-se o indivíduo como unidade estatística.

Para verificar a normalidade da distribuição das variáveis foi utilizado o teste de Kolmogorov-Smirnov e para a homogeneidade das variâncias foi utilizado o teste de Levene. Quando as variâncias eram homogêneas e a distribuição normal, utilizou-se o teste $t$ de Student para amostras pareadas para testar a igualdade das médias destas variáveis entre os grupos experimentais. No caso de nãonormalidade das observações, ou de variâncias não homogêneas, utilizou-se o teste não paramétrico de Wilcoxon.

Os dados coletados foram registrados em um banco de dados elaborado em programa Excel (versão 7.0). A análise estatística foi realizada em programa STATISTICA versão 5.1 e programa SPSS para Windows (versão 5.2).

Para todos os testes estatísticos assumiurse o nível de significância $\alpha$ de $5 \%$. 


\section{RESULTADOS}

Dentre os 11 participantes deste estudo, 3 eram do sexo masculino e 8 do sexo feminino, sendo que 3 (mulheres) declararam-se fumantes. A idade variou entre 28 a 50 anos $(\alpha=38,8 \pm 5,7)$. Este estudo contou com 45 defeitos sendo que 23 fizeram parte do grupo RET e 22 do grupo PME.

Tabela 5.1 - Média, mediana, desvio padrão e comparação dos grupos experimentais em relação à JEC-CO.

\begin{tabular}{|c|c|c|c|c|}
\hline & & PME & RET & $P$ \\
\hline Início & $\begin{array}{c}\mathrm{N} \\
\text { Média } \\
\text { Mediana } \\
\mathrm{DP}^{\dagger}\end{array}$ & $\begin{array}{l}11 \\
8,6 \\
6,0 \\
3,9\end{array}$ & $\begin{array}{l}11 \\
8,4 \\
7,0 \\
4,6\end{array}$ & $0,90^{\#}$ \\
\hline 1 ano & $\begin{array}{c}\mathrm{N} \\
\text { Média } \\
\text { Mediana } \\
\mathrm{DP}^{\dagger}\end{array}$ & $\begin{array}{c}11 \\
10,4 \\
10,0 \\
3,4\end{array}$ & $\begin{array}{l}11 \\
9,3 \\
5,0 \\
5,9\end{array}$ & $0,51^{ \pm}$ \\
\hline & $P$ & $0,02^{\# \star *}$ & 0,15 & \\
\hline
\end{tabular}

Os resultados demonstraram que no início do estudo não havia diferença entre os grupos. No grupo teste houve aumento significativo da medida JEC-CO após 1 ano $(p=0,02)$. No grupo controle também houve um aumento, embora este não tenha sido significativo. Não foram detectadas diferenças entre os grupos PME e RET após 1 ano. 
Tabela 5.2 - Média, mediana, desvio padrão e comparação dos grupos experimentais em relação à JEC-FD.

\begin{tabular}{ccccc}
\hline & & PME & RET & P \\
\hline \multirow{4}{*}{ Início } & $\mathrm{N}$ & 11 & 11 & \\
& Média & 15,3 & 13,5 & \\
& Mediana & 14,0 & 12,0 & $0,23^{\#}$ \\
& DP $^{\dagger}$ & 5,3 & 5,6 & \\
& & & & \\
\multirow{4}{*}{$\mathbf{1}$ ano } & $\mathrm{N}$ & 11 & 11 & \\
& Média & 15,9 & 12,1 & \multirow{2}{*}{$0,01^{\# *}$} \\
& Mediana & 14,0 & 9,0 & \\
& DP $^{\dagger}$ & 4,7 & 5,8 & \\
\hline & & & & \\
\hline
\end{tabular}

${ }^{\dagger} \mathrm{DP}=$ desvio padrão; \# teste t pareado; \pm teste de Wilcoxon; * diferença significativa a $5 \%$

No início do estudo não havia diferenças entre os grupos com relação a JECFD. Após 1 ano, houve um pequeno aumento desta medida no grupo PME, ao passo que no grupo RET foi observada certa diminuição. Em ambos os grupos estas mudanças não foram significativas. No entanto, após 1 ano, observoutse diferença estatisticamente significante entre os grupos $(p=0,01)$.

Tabela 5.3 - Porcentagens de mudança óssea dos grupos do estudo em relação às medidas JEC-CO e JEC-FD.

\begin{tabular}{c|cc}
\multicolumn{2}{c}{ MO (\%) } \\
\hline & JEC-CO & JEC-FD \\
\hline RET & $-10,71$ & 8,14 \\
PME & $-20,93$ & $-3,92$
\end{tabular}

Com relação às porcentagens de mudança óssea foi possível observar que o grupo RET mostrou uma média de perda da crista óssea alveolar de $-10,71 \%$ (JECCO) e um preenchimento ósseo do defeito de $8,14 \%$ (JEC-FD), enquanto que o grupo PME apresentou uma média de perda óssea, tanto para a JEC-CO quanto para a JEC-FD de -20,93\% e -3,92\%, respectivamente. 


\section{DISCUSSÃO}

O principal objetivo deste estudo foi avaliar através da análise por SRD linear em radiografias padronizadas o comportamento de defeitos infra-ósseos humanos tratados ou não com a PME, comparativamente, com o RET reposto. Dentre os trabalhos encontrados na literatura que utilizaram a mensuração radiográfica como forma de avaliação do resultado da PME, além do NCl, apenas Heijl et al (1997) utilizaram uma metodologia válida, segundo Esposito, Coulthard e Worthington (2005). Vale ressaltar que tal metodologia foi semelhante à empregada no presente estudo.

Observou-se que nenhum dos estudos que utilizaram mensuração radiográfica mostrou qual seria o grau de distorção entre as imagens, o que é considerado um artefato inerente à técnica. O limite aceitável para a realização da SRD é de $3^{\circ}$ entre as imagens (GRÖNDAHL; GRÖNDAHL; WEBBER,1994). Todavia, em nosso estudo não foi possível realizar este tipo de análise.

Um recurso que poderia ter sido utilizado para minimizar eventuais distorções é o alinhamento das imagens. Desta forma, a falta de alinhamento entre as imagens poderia ser considerada uma desvantagem do nosso método. A utilização deste artifício, já descrito na literatura (BYRD et al., 1998; JEFFCOAT; JEFFCOAT; WILLIAMS, 1984; WENZEL, 1989; YONN, 2000), tornaria nosso procedimento de mensuração ainda mais preciso.

Em relação à nossa amostra, notourse que dentre os 6 trabalhos encontrados na literatura 3 deles (OKUDA el al., 2000; PARASHIS;TSIKLAKIS, 2000; WINDISCH et al., 2002) utilizaram basicamente a mesma quantidade de pacientes que foi 
utilizada no presente estudo, sendo de 16, 15 e 12 pacientes, respectivamente. Os outros 3 estudos utilizaram amostras maiores, sendo de 24 pacientes no estudo de Pietruska (2001) e de 24 e 33 para os trabalhos de Francetti et al. (2004) e Heijl et al. (1997), respectivamente. Estes dois últimos tiveram períodos de avaliação maiores (2 e 3 anos).

Nossos resultados demonstraram que, do ponto de vista radiográfico, o tratamento de defeitos infra-ósseos de 2 ou 3 paredes com a PME não apresentou resultados superiores ao RET. Ao contrário, foi possível notar que para os dois parâmetros (JEC-FD e JEC-CO) o grupo RET demonstrou resultados melhores, após o período de avaliação de 1 ano. Isto significa que ocorreu maior preenchimento ósseo e menor reabsorção da CO neste grupo.

Houve perda óssea média significativa da CO em ambos os grupos, sendo que no grupo PME esta foi de $1,8 \mathrm{~mm}$ ou $-20,93 \%$ (Início $=8,6 \mathrm{~mm} ; 1$ ano=10,4 $\mathrm{mm} ; \mathrm{p}=0,02)$, enquanto que no grupo RET este valor foi de $0,9 \mathrm{~mm}$ ou $-10,71 \%$ (Início $=8,4 \mathrm{~mm} ; 1$ ano $=9,3 \mathrm{~mm} ; \mathrm{p}=0,15)$, embora não tenha existido diferença estatística entre os grupos $(p=0,51)$. Por outro lado, foi observada mínima alteração do nível ósseo no grupo PME em relação ao parâmetro JEC-FD, sendo que a variação de 0,6 mm ou -3,92\% (Início = 15,3 mm; 1 ano=15,9 mm; p=0,42) não foi estatisticamente significante. No grupo RET houve um ganho ósseo médio na ordem de 1,1 mm ou 8,14\% (Início = 13,5 mm; 1 ano = 12,4 mm; $\mathrm{p=0,09}$ ), sendo observada diferença estatística entre os grupos $(p=0,01)$. Estes resultados estão em desacordo com os poucos trabalhos citados na literatura que utilizaram a SRD (HEIJL et al.,1997; OKUDA et al., 2000; PARASHIS;TSIKLAKIS, 2000; WINDISCH et al, 2002; FRANCETTI et al., 2004) ou simplesmente o exame radiográfico convencional 
(PIETRUSKA, 2001) para a avaliação do resultado do tratamento de defeitos infraósseos de 1, 2 ou 3 paredes com a PME.

Okuda et al. (2000) comparou os resultados entre a PME e o placebo através da densidade óssea radiográfica, revelando superioridade de $20,2 \pm 16,6 \%$ contra $-3,94 \pm 23,3 \%$, respectivamente. Este trabalho utilizou o sistema de aquisição direta de imagens digitais Digora ${ }^{\circledR}$ (Soredex, Orion Corporation Ltd., Helsinki, Finland). No entanto, existem trabalhos (STASSINAKIS et al.,1995; YOUNG et al.,1996) que utilizaram um sistema semelhante, (RadioVisioGraphy-RVG), para a análise de precisão de diagnóstico de lesões induzidas e cálculo do volume de lesões ósseas e observaram que os sistemas de aquisição direta de imagens digitais não eram eficazes e precisos. Na verdade, isto ocorre por que os níveis de resolução da imagem são menores do que os conseguidos com o filme convencional, gerando artefatos e diferenças nos níveis de cinza entre as duas imagens (RAWLINSON; ELLWOOD; DAVIES, 1999), o que é especialmente importante, quando o objetivo é a análise da diferença de contraste entre as imagens. Idealmente, Okuda et al. (2000) deveria ter utilizado cunhas de alumínio (RUTTIMANN; WEBBER, 1987; WEBBER; RUTTIMANN; HEAVEN, 1990; ALLEN; HAUSMANN, 1996) para o ajuste indireto de contraste entre as radiografias (LEHMANN; GRÖNDAHL; BENN, 2000).

O presente estudo revelou perda óssea média não significante, de 0,6 mm para o grupo PME, após 1 ano de avaliação. Heijl et al. (1997) demonstraram um ganho ósseo médio de 0,9 mm em 8 meses, 2,2 mm em 16 meses e 2,6 mm em 36 meses. Windisch et al. (2002) demonstraram um ganho ósseo médio de 1,05 mm após 6 meses e Pietruska (2001) observou um ganho ósseo médio de 2,6 mm após 1 ano do tratamento. Novamente, em relação ao estudo de Heijl et al. (1997) foi observado que no grupo controle não houve mudanças significativas ao longo do 
período de avaliação do estudo, todavia, nosso trabalho revelou no grupo RET um ganho ósseo médio de 1,1 mm. Apesar de nossos resultados estarem em desacordo com os observados nestes estudos, não podem ser diretamente comparados a todos eles, haja vista que, apenas Heijl et al. (1997) utilizaram uma metodologia de mensuração considerada válida (ESPOSITO; COULTHARD; WORTHINGTON, 2005). Windisch et al. (2002) realizaram a mensuração em ROls com dimensão de 256 × 256 pixels e Pietruska (2001) utilizou apenas um negatoscópio associado a uma lente de 2 vezes e meia de aumento.

No presente estudo, quando transformamos nossos resultados em números percentuais, o grupo PME revelou uma perda óssea média de $-3,92 \%$ após 1 ano, ao passo que, Parashis e Tsiklakis (2000) mostraram após o mesmo período um preenchimento ósseo médio de 22,9\% em 25 defeitos infra-ósseos e Francetti et al. (2004) após 2 anos observaram preenchimento na ordem de 57\%. Por outro lado, para o grupo RET foi observado um ganho ósseo médio de $8,14 \%$, enquanto que para Francetti et al. (2004) este valor foi na ordem de 38\%, após 2 anos de acompanhamento. Vale ressaltar que o estudo de Francetti et al. (2004) não apresentou diferença estatística após 1 ano de avaliação, com valores de preenchimento ósseo de $49 \%$ para o grupo teste e $30 \%$ para o grupo controle.

Uma das questões relevantes em relação ao estudo de Francetti et al. (2004) foi mencionada na revisão sistemática de Esposito, Coulthard e Worthington (2005). Estes autores comentaram da limitação na interpretação dos dados, pois o ponto de referência anatômico utilizado para a mensuração foi a $\mathrm{CO}$, sendo esta considerada mutável. Este parâmetro também foi adotado por Pietruska (2001) revelando a mesma limitação para a interpretação de seus dados. 
Em relação à $\mathrm{CO}$ o presente ensaio clínico mostrou uma perda óssea para o grupo PME de $-20,93 \%$, sendo que dentre os estudos citados anteriormente, apenas Parashis e Tsiklakis (2000) relataram uma perda da CO na ordem de $-20,7 \%$, assemelhando-se aos nossos resultados. Windisch et al (2002) apresentaram seus resultados em milímetros, revelando $0,33 \mathrm{~mm}$ de perda de $\mathrm{CO}$ no grupo tratado com a PME, enquanto nosso estudo mostrou uma perda da CO no valor médio de 1,8 $\mathrm{mm}$.

A inclusão de pacientes fumantes na amostra poderia ter contribuído para resultados inferiores no grupo PME uma vez que o ganho de altura óssea em indivíduos fumantes mostra-se menor em comparação a indivíduos não-fumantes, quando tratados cirurgicamente (BOSTROM; LINDER; BERGSTROM, 1998), como também, quando submetidos a procedimentos regenerativos (TONETTI; PINIPRATO; CORTELLINI, 1995; CORTELLINI; PINI-PRATO; TONETTI, 1996; TROMBELLI et al., 1997), talvez justificando a maior taxa de reabsorção da CO no grupo PME. Outro aspecto em relação ao fumo é que a comparação entre os sujeitos fumantes e não-fumantes não foi possível de ser abordada devido ao pequeno número da amostra. A análise da literatura mostrou que diversos trabalhos também utilizaram pacientes fumantes em suas amostras e não realizaram a comparação dos resultados radiográficos entre eles (HEIJL et al., 1997; PARASHIS; TSIKLAKIS, 2000; WINDISCH et al., 2002; FRANCETTI et al., 2004), sendo que apenas Okuda et al. (2000) trabalharam exclusivamente com pacientes nãofumantes.

Com exceção ao trabalho de Parashis e Tsiklakis (2000), que utilizaram um programa já utilizado e descrito na literatura (EMAGO/ Advanced v 3.1) para a realização de SRD, todos os outros trabalhos utilizaram programas relativamente 
desconhecidos (Argus 10; NIH image public domain v 1.61; MSRL Universidade da Flórida e Scion Image). Isto pode ser explicado, pois em recente revisão da literatura, Pasin, Chambrone e Lima (2004) relataram que existem apenas dois centros (Jeffcoat M - Alabama, EUA e Brägger U - Berna, Suíça) que utilizam programas validados cientificamente e que não são disponibilizados comercialmente. Em nosso estudo foi utilizado com sucesso um programa originalmente utilizado para histometria (Axio-Vision v 3.0). Uma vez que ele disponibiliza a criação de escalas de mensuração foi possível realizá-la com precisão milimétrica, devido à calibração obtida anteriormente na tela radiográfica. Esses resultados foram confirmados por mensuração independente realizada pelo grupo da Universidade de Berna (LANG, N) utilizando o programa Image Tool (UTHSC - Universidade do Texas, Health and Science Center) (Dados não apresentados).

Em relação ao condicionamento da superfície radicular, a aplicação do EDTA a 24\% (Prefgel) foi realizada apenas no grupo PME, o qual é considerado o protocolo estabelecido pelo fabricante do Emdogain ${ }^{\circledR}$. Os trabalhos de Pietruska (2001), Windisch et al. (2002) e Francetti et al. (2004) seguiram este protocolo, embora existam trabalhos que não utilizaram nenhum tipo de tratamento radicular antes da aplicação do PME, como é o caso de Parashis e Tsiklakis (2000). Há também estudos que utilizaram outros agentes como, por exemplo, o ácido fosfórico a 37\% (HEIJL et al., 1997; OKUDA et al., 2000). Uma das vantagens da utilização do EDTA está relacionada a sua característica de não danificar os tecidos circunjacentes ao defeito infra-ósseo (BLOMLOF et al., 1996; BLOMLOF; BLOMLOF; LINDSKOG, 1997). No presente trabalho, optou-se por não utilizar nenhum agente condicionante nas raízes dos dentes do grupo RET, afim de não 
incluir mais um fator de variação e avaliar exclusivamente o resultado da técnica cirúrgica. Além disso, Stahl, Froum e Kushner (1983) demonstraram que o condicionamento radicular não beneficia o tratamento de defeitos infra-ósseos de maneira universal.

A maioria dos trabalhos analisados (HEIJL et al., 1997; OKUDA et al., 2000; PARASHIS; TSIKLAKIS, 2000; PETRUSKA, 2001; WINDISCH et al., 2002, FRANCETTI et al., 2004) utilizou algum tipo de antibioticoterapia pós-cirúrgica. Todavia, no presente estudo não se utilizou antibioticoterapia com o objetivo de isolar os efeitos da PME, o que está de acordo com a metodologia utilizada por Tonetti et al. (2002), os quais publicaram resultados equivalentes aos estudos que utilizaram este artifício pós-cirúrgico. Além disso, a não utilização de antibióticos no tratamento com a PME pode ser justificada, uma vez que Sculean et al. (2001) não observaram resultados estatisticamente superiores para a retração gengival e o $\mathrm{NCl}$.

Embora a ausência da utilização da antibioticoterapia pudesse ter favorecido a influência bacteriana nos períodos iniciais da reparação tecidual, todos os indivíduos foram submetidos à cirurgia com um $\mathrm{IP} \leq 20 \%$. Além disso, utilizourse gluconato de clorexidine $(0,12 \%$ duas vezes ao dia) durante as primeiras 4 semanas e todos os pacientes foram monitorados semanalmente durante as primeiras 8 semanas, excluindo-se a hipótese inicial.

Outro aspecto que poderia justificar os resultados não satisfatórios para a PME é a técnica cirúrgica. Nos estudos de Tonetti et al. (2002) e Francetti et al. (2004) foi utilizada a técnica cirúrgica de preservação papilar mostrando resultados satisfatórios. Heijl et al. (1997) utilizaram o retalho de Widman modificado também mostrando resultados superiores da PME sobre o controle. Apesar dos outros trabalhos (OKUDA et al., 2000; PARASHIS; TSIKLAKIS, 2000; PIETRUSKA, 2001; 
WINDISCH et al., 2002) não descreverem com exatidão a técnica cirúrgica utilizada por eles, os resultados mostraram-se novamente superiores para os grupos tratados com a PME. Neste trabalho foi utilizada a incisão intra-sulcular na tentativa de preservar a maior quantidade possível de tecidos. Mesmo assim, nossos resultados não se mostraram semelhantes aos relatados na literatura. Desta forma, é possível inferir que a técnica cirúrgica possa ter grande influência sobre os resultados do tratamento de defeitos infra-ósseos com a PME, havendo a necessidade de ensaios clínicos controlados que avaliem melhor esta hipótese.

Em relação aos dados clínicos, observou-se redução da PCS de 4,0 mm para o grupo PME e de 3,6 mm para o grupo RET, sendo estatisticamente significantes, porém não houve diferença entre os grupos $(\mathrm{p}=0,33)$. Em relação ao $\mathrm{NCl}$, houve redução de 3,4 e 3,3 mm, respectivamente, novamente não mostrando dferença entre os grupos. Com base nestes dados é possível afirmar que existiu reprodutibilidade para ambos os métodos de mensuração ( $\mathrm{NCl}$ e SRD linear), o que reforça a confiabilidade da metodologia empregada no estudo. Além disso, também é possível afirmar que a avaliação dos dados clínicos e radiográficos mostrou que ambos os tratamentos foram equivalentes (CHAMBRONE, 2003).

Baseado nos fatores citados anteriormente e na evidente heterogeneidade dos estudos é plausível inferir que não há, no momento, significância clínica que justifique a utilização da PME na clínica diária. Tal posicionamento está de acordo com Esposito, Coulthard e Worthington (2005), pois estes autores ressaltaram que existe heterogeneidade entre os estudos e ela se reflete numa alta variabilidade de resultados, sendo que os dados não explicam esta variabilidade. Estes mesmos autores, através da meta-análise de 8 ensaios clínicos controlados e randomizados, demonstraram uma redução média da PCS igual a $1 \mathrm{~mm}(95 \%$ IC: 0,5 a 1,4 mm) e 
um ganho médio no $\mathrm{NCl}$ de 1,3 mm (95\% IC: 0,8 a 1,8 mm), sugerindo que estes resultados não têm grande impacto clínico, pois dentes com comprometimento periodontal mais avançado não poderiam ser salvos com base nestes resultados.

Vale ainda ressaltar que a variabilidade dos resultados pode estar relacionada com o local de realização do estudo, a inclusão de pacientes fumantes, o tipo de doença tratada, a resposta do paciente frente ao tratamento, a persistência de patógenos específicos, as diferenças na habilidade técnica e na experiência dos clínicos (TONETTI et al., 2002), a utilização de placebo, de antibioticoterapia, de diferentes técnicas cirúrgicas e de diferentes agentes para o condicionamento radicular (ESPOSITO; COULTHARD; WORTHINGTON, 2005).

Desta maneira, acredita-se que sejam necessários mais ensaios clínicos controlados, que avaliem os efeitos da PME a longo prazo, objetivando verificar o real efeito da PME sobre o periodonto. Este posicionamento está de acordo com Wang Hom-Lay (2005) que ressaltaram a necessidade de mais estudos para avaliação do mecanismo de ação, do potencial regenerativo e para a determinação do real benefício a longo prazo da PME. 


\section{CONCLUSÕES}

Considerando as limitações deste estudo pode-se concluir que:

A análise por SRD linear demonstrou que o tratamento de defeitos infraósseos de 2 ou 3 paredes por meio de RET mostrou-se superior em comparação à aplicação da PME, revelando maior preenchimento ósseo dos defeitos, após o período de 1 ano. 


\section{REFERÊNCIAS ${ }^{1}$}

Allen KM, Hausmann E. Analytical methodology in quantitative digital subtraction radiography: Analyses of the aluminum reference wedge. J Periodontol 1996;67:1317-21.

Ando S, Nishioka T, Ozawa M, Yamano H, Shinoda K. Computer analysis of radiographic images. J Nihon Univ Sch Dent 1968;10(2):65-70.

Ando S, Nishioka T, Shinoda K, Yamano H, Ozawa M. Computerzed numerical evaluation of radiographic images: The destruction and reduction of bone tissues in periodontal areas. J Nihon Univ Sch Dent 1969;11:41-7.

Armitage GC. International Workshop for a classification of periodontal diseases and conditions. Ann Periodontol 1999;4:1-6.

Benn DK. Limitations of the digital image subtraction technique in assessing alveolar bone crest changes due to misalignment errors during image capture.

Dentomaxillofac Radiol 1990; 19: 97-104.

Blomlof J, Jansson L, Blomlof L, Lindskog SF. Root surface etching at neutral pH promotes periodontal healing. J Clin Periodontol 1996;23(1):50-5.

Blomlof J, Blomlof L, Lindskog SF. Effect of different concentrations of EDTA on smear removal and collagen exposure in periodontitis-affected root surfaces. J Clin Periodontol 1997;24(8):534-7.

Brägger U, Litch J, Pasquali L, Kornman KS. Computer assisted densitometric image analysis for the quantification of radiography alveolar bone changes. J Periodontal Res 1987;22:227-9.

Brägger D, Pasquali L, Rylander H, Carnes D, Kornman KS. Computer-assisted densitometric image analysis in periodontal radiography. J Clin Periodontol 1988;15:27-37.

\footnotetext{
${ }^{1}$ De acordo com Estilo Vancouver. Abreviatura de periódicos segundo base de dados MEDLINE.
} 
Brägger U. Digital imaging in periodontal radiography. J Clin Periodontol 1988;15:551-7.

Brägger U, Pasquali L. Color conversion of alveolar bone density changes in digital subtraction images. J Clin Periodontol 1989;16:209-14.

Brägger U, Bürgin W, Marconi M, Häsler RU, Lang NP. Influence of contrast in enhancement and pseudocolor transformation on the diagnosis with subtraction images. J Periodont Res 1994;29:95-102.

Brägger U, Bürgin W, Fourmousis I, Schmid G, Schild U, Lang NP. Computerassisted densitometric image analysis of digital subtraction images: in vivo error of the methody and effect of thresholding. J Periodontol 1998;69:967-74.

Brostrom L, Linder LE, Bergstrom J. Influence of smoking on the outcome of periodontal surgery. A 5-year follow-up. J Clin Periodontol 1998;25:194-201.

Byrd V, Mayfield-Donahoo T, Reddy MS, Jeffcoat MK. Semiautometed image registration for digital subtraction radiography. Oral Surg Oral Med Oral Pathol Oral Radiol Endod 1998;85(4-6):473-8.

Chambrone D. Tratamento de defeitos infra-ósseos de 2 ou 3 paredes com retalho de espessura total reposto associado ou não à proteína da matriz do esmalte. Estudo clínico em humanos [Dissertação de Mestrado]. Faculdade de Odontologia de São Paulo; 2003.

Chaves ES, Geurs NC, Reddy MS, Jeffcoat MK. Clinical and radiographic digital imaging evaluation of a bioresorbable membrane in treatment of periodontal bone defects. Int J Periodontics Restorative Dent 1996;16(5):443-53.

Christgau M, Schmalz G, Reich E, Wenzel A. Clinical and radiographical split-mouthstudy on resorbable versus non-resorbable GTR-membranes. J Clin Periodontol 1995;22:306-15.

Christgau M, Wenzel A, Hiller KA, Schmalz G. Quantitative digital subtraction radiography for assessment of bone density changes following periodontal guided tissue regeneration. Dentomaxillofac Radiol 1996;25(1):25-33. 
Christgau M, Hiller KA, Schnalz G, Kolbecka C, Wenzel A. Accuracy of quantitative digital subtraction radiography for determining changes in calcium mass in mandibular bone: An in vitro study. J Periodont Res 1998;33:138-49.

Christgau M, Bader N, Felden A, Gradl J, Wenzel A, Schmalz G. Guided tissue regeneration in intrabony defects using an experimental bioreorbable polydioxanon (PDS) membrane - A 24 -month split-mouth study. J Clin Periodontol 2002;29(8):71023.

Cortellini P, Pini-Prato GP, Tonetti MS. Long-term stability of clinical attachment following guided tissue regeneration and conventional therapy. J Clin Periodontol 1996;23:106-11.

Dubrez B, Duroux P, Cimasoni G. Bone density of class II furcation lesions treated by guided tissue regeneration. J Clin Periodontol 1996;23:882-8.

Duckworth JE, Judy PF, Goodson JM, Socransky SS. A method for the geometric and densitometric standardization of intraoral radiographs. J Periodontol 1983;54(79):435-40.

Eickholz P, Hausmann E. Evidence for healing of class II and III furcations after GTR therapy: digital subtraction and clinical measurements. J Periodontol 1997;68:636-44.

Eickholz P, Hausmann E. Evidence for healing of interproximal intrabony defects after conventional and regenerative therapy: digital radiography and clinical measurements. J Periodont Res 1998;33:156-65.

Eickholz P, Hausmann E. Evidence for healing of class II and III furcations 24 months after guided tissue regeneration therapy: digital subtraction and clinical measurements. J Periodontol 1999;70:1490-1500.

Esposito M, Coulthard P, Worthington HV. Enamel matrix derivative $\left(\right.$ Emdogain $^{\circledR}$ ) for periodontal tissue regeneration in intrabony defects (Cochrane Review). In: The Cochrane Library, issue 2, 2005.

Francetti L, Del Fabbro, Basso M, Testori T, Weinstein R. Enamel matrix proteins in the treatment of intrabony defects. A propesctive 24-month clinical trial. J Clin Periodontol 2004;31:52-9. 
Graves DT. The use of biologic response modifiers in human clinical trials. Ann Periodontol 1997;2:259-67.

Griffiths GS, Brägger U, Fourmousis I, Sterne JAC. Use of an internal standard in subtraction radiography to assess initial periodontal bone changes. Dentomaxillofac Radiol 1996;25(2):76-81.

Gröndahl H, Gröndahl K, Webber RL. A digital subtraction technique for dental radiography. Oral Surg Oral Med Oral Pathol 1983; 55(1): 92-102.

Gröndahl H, Gröndahl K. Subtraction radiography for the diagnosis of periodontal bone lesions. Oral Surg Oral Med Oral Pathol 1983:55(2):208-13.

Gröndahl K, Gröndahl H, Wenntröm J, Heijl L. examiner agreement in estimating changes in periodontal bone fro conventional and subtraction radiographs. J Clin Periodontol 1987; 14:74-9.

Hardstedt Ch, Welander U. Photographic subtraction. Theory of the subtraction image. Acta Radiologica Diagnosis 1974;16(6):559-64.

Hausmann E, Dunford R, Wikesjo U, Christersson L. Assessment of the progression of untreated periodontitis by subtraction radiography [abstract 526]. J Dent Res 1985a;65:228.

Hausmann E, Christersson L, Dunford R, Wikesjo U, Phyo J, Genco J. Us efilness of subtraction radiography in the evaluation of periodontal therapy. J Periodontol 1985b; 56(10-12):4-7.

Hausmann E, Dunford R, Wikesjo U, Christersson L, McHenry K. Progression of untreated periodontites as assessed by subtraction radiography. J Periodontal Res 1986;21:716-21.

Heijl L, Heden G, Svärdström G, Östgren A. Enamel matrix deruvative $\left(\right.$ EMDOGAIN $\left.{ }^{\circledR}\right)$ in treatment of intrabony periodontal defects. J Clin Periodontol 1997;24:705-14.

Jeffcoat MK, Jeffcoat RL, Willimas RC. A new method for the comparison of bone loss measurements on non-standardized radiographs. J Periodontal Res 1984;19(46):434-40. 
Jeffcoat MK, Webber RL, Reddy M, Williams RC. Digital subtraction radiology without stents [abstract 57]. J Dent Res 1985;65:176.

Jeffcoat MK, Reddy MS, Webber RL, Williams RC, Ruttimann UE. Extraoral control of geometry for digital subtraction radiography. J Periodontal Res 1987;22(4-6):396402.

Jeffcoat M K. Radiographic methods for the detection of progressive alveolar bone loss. J Periodontol 1992;63:367-72.

Jeffcoat MK, Wang IC, Reddy MS. Radiographic diagnosis in periodontics. Periodontology 2000 1995;7:54-68.

Jeffcoat MK, Reddy MS, Magnusson I, Johnson B, Meredith MP, Cavanaugh Jr PF, et al. Efficacy of quantitative digital subtraction radiography using radiographs exposed in a multicenter trial. J Peridont Res 1996;31:157-60.

Jeffcoat MK, Reddy MS. Advances in measurements of periodontal bone and attachment loss. Monogr Oral Sci 2000;17:56-72.

Kirkwood BR. Essentials of medical statistics. Oxford: Blackwell Scientific; 1988:224.

Kullendorf B, Gröndahl K, Rohlin M, Henrikson CO. Subtraction radiography for the diagnosis of periapical boe lesions. Endod Dent Traumatol 1988;4(4-6):253-9.

Kullendorf B, Gröndahl K, Rohlin M, Nilsson M. Subtraction radiography of interradicular bone lesions. Acta Odontol Scand 1992;50:259-67.

Lehmann TM, Gröndahl HG, Benn DK. Computer-based registration for digital subtraction in dental radiology. Dentomaxillofacial Radiol 2000;29:323-46.

Löe $\mathrm{H}$. The gingival index, the plaque index and the retention index system. J Periodontol 1967;38:10-6.

Nicopoulou-Karayianni K, Brägger U, Bürgin W, Nielsen PM, Niklaus PL. Diagnosis of alveolar bone changes with digital subtraction images and conventional radiographs. Oral Surg Oral Med Oral Pathol 1991;72:251-6. 
Okuda K, Momosi M, Miyazaki A, Murata N, Yokoyama S, Wonezawa Y, et al. Enamel matrix derivative in the treatment of human intrabony osseous defects. $\mathrm{J}$ Periodontol 2000;71:1821-8.

O'Leary TJ, Ruddy KD. An instrument for measuring horizontal mobility. Periodontics 1963;1:249.

Papapanou PN, Wennström JL, Gröndahl K. Periodontal status in relation to age and tooth type. A cross-sectional radiographic study. J Clin Periodontol 1988;15:469-78.

Parashis A, Tsiklakis K. Clinical and radiographic findings following application of enamel matrix derivative in the treatment of intrabony defects. A series of case reports. J Clin Periodontol 2000;27:705-13.

Pasin IM, Chambeone D, Lima LAPA. A utilização da subtração radiográfica digital (SRD) em Periodontia - Estado atual. Rev Periodontia 2004;14(4):48-53.

Pietruska MD. A comparative study on the use of Bio-Oss and enamel matrix derivative $\left(\right.$ Emdogain $\left.^{\circledR}\right)$ in the treatment of periodontal bone defects. Eur J Oral Sci 2001;109:178-81.

Putnins E, Lavelle CLB, Holthuis A. Detection of tree-walled infrabony defects by subtraction radiography. Oral Surg Oral Med Oral Pathol 1988;65(1-3):102-8.

Rawlinson A, Ellwood RP, Davies RM. An in-vitro evaluation of a dental subtraction radiography system using bone chips on dried human mandibles. J Clin Periodontol 1999; 26(1-3):138-42.

Reddy MS, Bruch JM, Jeffcoat MK, Williams RC. Contrast enhancement as an aid to interpretation in digital subtraction radiography. Oral Surg Oral Med Oral Pathol 1991;71:763-9.

Reddy MS. Radiographic methods in the evaluation of periodontal therapy. J Periodontol 1992;63:1078-84.

Reddy MS, Jeffcoat MK. Digital subtraction radiography. Dent Clin North Am 1993;37(4):553-65. 
Rethman M, Ruttimann U, O`Neal R, Webber R, Davis A, Greenstein G et al. Diagnosis of bone lesions by subtraction radiography. J Periodontol 1985a;56(6):324-9.

Rethman MP, O'Neal RB, Woodyard SG, Vincent JW, Hollinger JO, Webber RL. Subtraction radiographic change following periodontal therapy in Reshus monkey [abstract 315]. J Dent Res 1985b;64:209.

Rudolph D, White SC, Mankovich NJ. Effect of exposure parameters on digital subtraction imaging [abstract 59]. J Dent Res 1985;65:176.

Rudolph D J, White S C. Film-holding instruments for intraoral subtraction radiography. Oral Surg Oral Med Oral Pathol 1988;65:767-72.

Ruttimann U, Richard L, Webber RL, Schmidt E. A robust digital method for film contrast correction in subtraction radiography. J Periodontal Res 1986;21:486-95.

Ruttimann UE, Webber RL. Volumetry of localized bone lesions by subtraction radiography. J Periodontal Res 1987;22:215-6.

Schmidt E, Loesche W, Webber RL. Effect of periodontal therapy on alveolar bone as measured by subtraction radiography [abstract 525]. J Dent Res 1985;65:228.

Schmidt E, Webber RL, Ruttimann UE, Loesche WJ. Effect of periodontal therapy on alveolar bone as measured by subtraction radiography. J Periodontol 1988;59(1012):633-8.

Sculean A, Blaes A, Arweiller N, Reich E, Donos N, Brecx M. The effect of post surgical antibiotics on the healing of intrabony defects following treatment with enamel matrix proteins. J Periodontol 2001;72(2):190-5.

Silness J, Löe H. Periodontal disease in pregnancy. II. Correlation between oral hygiene and periodontal condition. Acta Odontol Scand 1964;22:121-35.

Stahl SS, Froum SJ, Kushner L. Healing responses of human intraosseous lesions following the use of debridement, grafting and citric acid root treatment. II. Clinical and histologic observations: One year post-surgery. J Periodontol 1983;54:325-38. 
Stassinakis A, Brägger U, Stojanovic M, Bürgin W, Lussi A, Lang NP. Accuracy in detecting bone lesions in vitro with conventional and subtracted direct digital imaging. Dentomaxillofac Radiol 1995;24(4):232-7.

Steffensen B, Pasquali LA, Yuan C, Wood RC, Schoolfield JD, Kornman KS. Correction of density changes acused by methodological errors in CADIA. J Periodont Res 1989;24:402-8.

Steffensen B, Brägger U, Yuan C, Pasquali LA, Brunsvold M, Kornman KS. Effect of region-of-interest in computerized densitometric análisis of radiographs. J Perodont Res 1991;26:107-13.

Tonetti MS, Pini-Prato G, Cortellini P. Effect of cigarette smoking on long -term clinical results of intra-bony defects treated with regenerative therapy. A preliminary retrospective study. J Clin Periodontol 1995;22:229-34.

Tonetti MS, Lang NP, Cortellini P, Suvan JE, Adriaens P, Dubravec D, et al. Enamel matrix proteins in the regenerative therapy of deep intrabony defects. J Clin Perodontol 2002;29(4):317-25.

Trombelli L, Kim CK, Zimmerman GJ, Wikesjo UME. Retrospective analysis of factors related to clinical outcome of guided tissue regeneration procedures in intrabony defects. J Clin Periodontol 1997;24:366-71.

Vos MH, Janssen PTM, Aken J, Heethaar RM. Quantitative measurement of periodontal bone changes by digital subtraction. J Periodontal Res 1986;21:583-91.

Wang Hom-Lay. Periodontal Regeneration. Position Paper. J Periodontol 2005;76:1601-22.

Webber RL, Ruttimann UE, Gröndahl H. X-ray image subtraction as a basis for assessment of periodontal changes. J Periodontal Res 1982;17:509-11.

Webber RL, Ruttimann UE, Heaven TJ. Calibration errors in digital subtraction radiography. J Periodont Res 1990;25:268-75.

Wenzel A. Effect of manual compared with reference point superimposition on image quality in digital subtraction radiography. Dentomaxillofc Radiol 1989;18:145-50. 
Wenzel A. Influence of computerized information technologies on image quality in dental radiographs. Danish Dent J 1991;12:1-26.

Windisch P, Sculean A, Klein F, Tóth V, Gera I, Reich E, et al. Comparision of clinical, radiographic and histometric measurements following treatment with guided tissue regeneration or enamel matrix proteins in human periodontal defects. $\mathrm{J}$ Periodontol 2002;73:409-17.

Yoon DC. A new method for the automated alignment of dental radiographs for digital subtraction radiography. Dentomaxillofac Radiol 2000;29(11):11-9.

Young SJ, Chaibi MS, Graves DT, Majzoub Z, Boustany F, Cochran D et al. Quantitative analysis of periodontal defects in a skull model by subtraction radiography using a digital imaging device. J Periodontol 1996;67:763-9.

Zappa $\mathrm{U}$, Simona $\mathrm{C}$, Graf $\mathrm{H}$, Aken J. In vivo determination of radiographic projection errors produced by a novel filmholder and $\mathrm{x}$-ray beam manipulator. $\mathrm{J}$ Periodontol $1991 ; 62(11): 674-83$.

Zappa U, Simona C, Graf H, Aken J. Time-related changes of in vivo projection errors in standardized radiographs. J Periodontol 1993;64(4):278-84. 
ANEXO A - Carta de aprovação do comitê de ética em pesquisa

\section{Faculdade de Odontologia \\ Universidade de São Paulo}

PARECER n $n^{\circ} 215 / 03$

Protocolo 220/03

O Grupo de Trabalho indicado pelo Comitê de Ética em Pesquisa, APROVOU o protocolo de pesquisa "Avaliação radiográfica por subtração digital de radiografias de defeitos infra-ósseos humanos de 2 ou 3 paredes tratados com proteina na matriz do esmalte", de responsabilidade do Prof. Dr. Luiz Antonio Pugliesi Alves de Lima

Tendo em vista a legislaçäo vigente, devem ser encaminhados a este Comitê relatórios anuais referentes ao andamento da pesquisa e ao término cópia do trabalho em "cd". Qualquer emenda do projeto original deve ser apresentada a este CEP para apreciaçăo, de forma clara e sucinta, identificando a parte do protocolo a ser modificada e suas justificativas.

Săo Paulo, 03 de dezembro de 2003

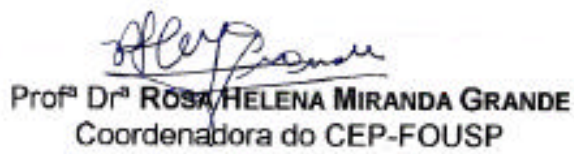

Av. Prof. Lineu Prestes, 2227 - Cidade Universitária "Armando de Salles Oliveira" CEP 05508-900 S3ao Paulo - SP Diretoria Telofax (011) 38140062 - 30917817/60 
Este termo se destina a esclarecer ao participante sobre a pesquisa "Estudo clínico comparativo, em humanos, da reparação de defeitos infra-ósseos de 2 ou 3 paredes utilizando uma membrana absorvível ou proteína da matriz do esmalte", a ser desenvolvida pela C.D. Daniela Chambrone.

No tratamento da doença periodontal (doença que afeta gengiva e osso de suporte dos dentes), existem várias técnicas para reconstrução dos tecidos afetados. Algumas destas técnicas utilizam um tipo de membrana ou um material contendo proteína para melhorar a cicatrização (ou reparação) dos tecidos. Este estudo tem o objetivo de comparar 3 diferentes técnicas de tratamento, através de acompanhamento clínico e radiográfico.

Os pacientes que concordarem em participar da pesquisa responderão a um questionário de saúde e passarão por exames clínicos, radiográficos, controle de placa bacteriana, orientação de higiene bucal e procedimentos de raspagem e alisamento radicular de todos os dentes com o periodonto comprometido. Após esta primeira parte do tratamento, novos dados clínicos e radiográficos serão coletados observando-se as áreas com necessidade cirúrgica. Esses dados serão comparados com os resultados coletados após 6 meses do tratamento cirúrgico. Serão feitas fotografias das áreas a serem tratadas pela cirurgia .

Após o tratamento cirúrgico haverá acompanhamento semanal nas primeiras 06 semanas e mensal até 6 meses. Em seguida a este período os pacientes entrarão num programa de controle e manutenção na Clínica de Pós-Graduação em Periodontia da Universidade de São Paulo.

No decorrer do tratamento, em alguns casos, é possível que ocorra algum desconforto, como dor, e presença de pus na região em tratamento. Frente a isto ou a qualquer outro imprevisto durante o tratamento, o paciente receberá todo amparo necessário, entrando em contato com Daniela Chambrone - fone: 8187904 (Clínica de Periodontia - USP) ou no 69653590 .

A identificação do paciente será preservada de forma que seu nome não aparecerá nas publicações subseqüentes à pesquisa, nem será citado em cursos, palestras ou aulas expositivas. O paciente não receberá e não efetuará nenhum pagamento pela sua participação na pesquisa.

Fica claro que o paciente terá o direito de desistir de participar da pesquisa a qualquer momento de forma a imperar o seu livre arbítrio, sem prejuízo de qualquer benefício que esteja recebendo.

NOME:

R.G.:

DATA NASC.:

ENDEREÇO:

CEP: DATA DE EXPEDIÇÃ̃: FONE:

Declaro estar de pleno acordo com os termos acima e optar pela participação voluntária da pesquisa supracitada. 